\title{
Scaling up family planning in Zambia-Part 1: Assessment and feasibility of maintaining an innovative program
}

\author{
Benjamin Bellows \\ Population Council \\ Mary Nambao \\ Luigi Jaramillo \\ Roz Fanaiayan \\ Mardieh Dennis
}

See next page for additional authors

Follow this and additional works at: https://knowledgecommons.popcouncil.org/departments_sbsr-rh

Part of the Demography, Population, and Ecology Commons, Family, Life Course, and Society Commons, International Public Health Commons, and the Women's Health Commons How does access to this work benefit you? Let us know!

\section{Recommended Citation}

Bellows, Benjamin, Mary Nambao, Luigi Jaramillo, Roz Fanaiayan, Mardieh Dennis, and Karen Hardee. 2016. "Scaling up family planning in Zambia-Part 1: Assessment and feasibility of maintaining an innovative program," Research report. Washington, DC: Population Council, Evidence Project. 
Authors

Benjamin Bellows, Mary Nambao, Luigi Jaramillo, Roz Fanaiayan, Mardieh Dennis, and Karen Hardee 


\section{USAID}

\section{Evidence}

\section{Scaling Up Family Planning in Zambia}

0
0
1
7
0
0
0
0
0
0
0

\section{PART 1: ASSESSMENT AND FEASIBILITY OF MAINTAINING AN INNOVATIVE PROGRAM}

Ben Bellows, Associate II, Population Council, Zambia

Mary Nambao, Deputy Director, $\mathrm{MCH}$, Ministry of Community Development Mother and Child Health, Zambia

Luigi Jaramillo, Monitoring and Evaluation Specialist, Management Sciences for Health, USA Roz Fanaiayan, Graduate Student, University of California at Los Angeles, USA

Mardieh Dennis, PhD student, Faculty of Epidemiology and Population Health, London School of Hygiene and Tropical Medicine, UK

Karen Hardee, Director, The Evidence Project, Population Council, USA

\section{MAY 2016}

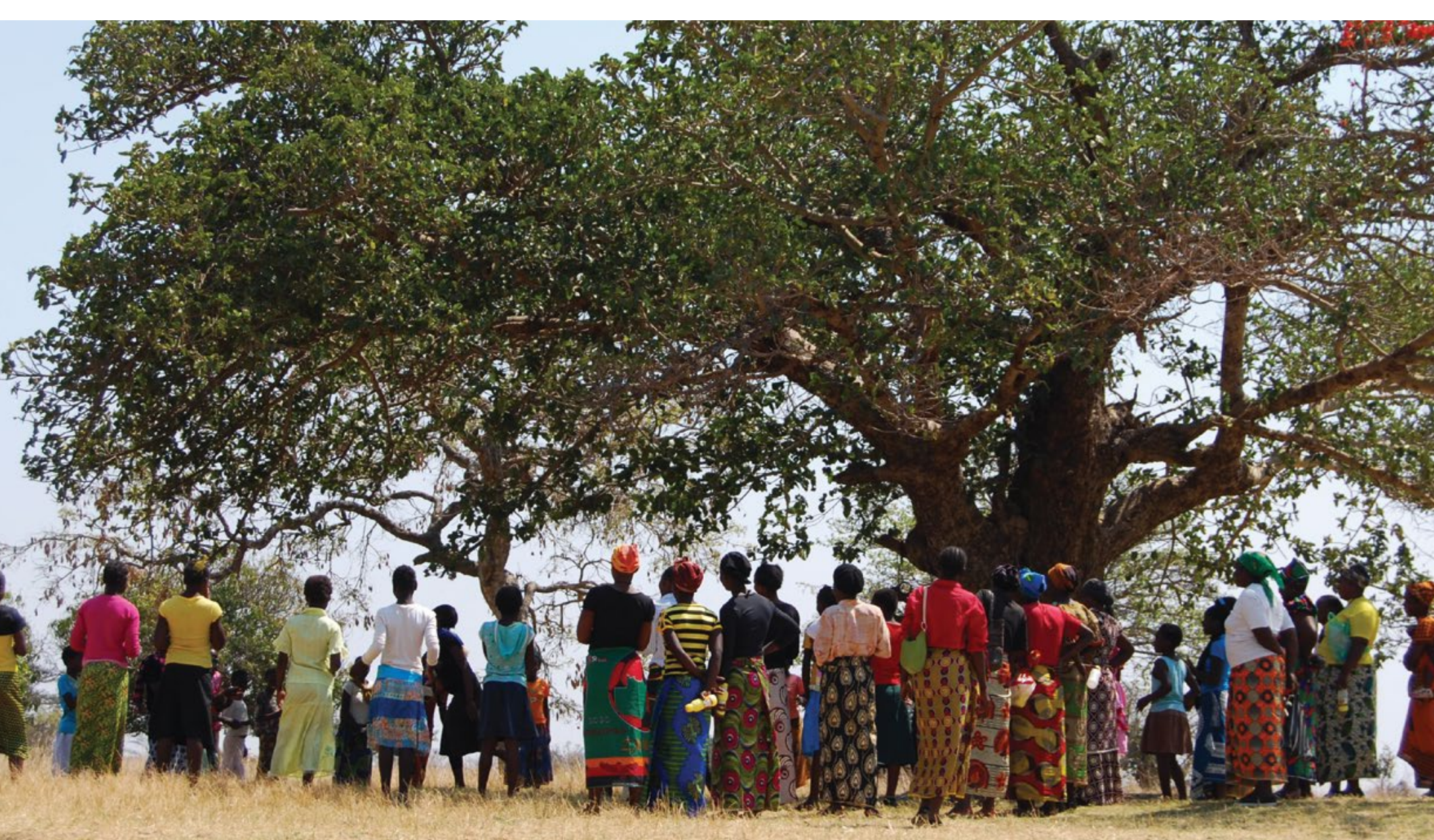


The Evidence Project

Population Council

4301 Connecticut Avenue, NW, Suite 280

Washington, DC 20008 USA

tel +12022379400

evidenceproject.popcouncil.org

The Evidence Project is made possible by the generous support of the American people through the United States Agency for International Development (USAID) under the terms of cooperative agreement no. AID-

OAA-A-13-00087. The contents of this document are the sole responsibility of the Evidence Project and Population Council and do not necessarily reflect the views of USAID or the United States Government.

Evidence

The Evidence Project uses implementation science-the strategic generation, translation, and use of evidence-to strengthen and scale up family planning and reproductive health programs to reduce unintended pregnancies worldwide. The Evidence Project is led by the Population Council in partnership with INDEPTH Network, International Planned Parenthood Federation, PATH, Population Reference Bureau, and a University Research Network.

Published in May 2016.

Suggested citation: Bellows, Ben, Mary Nambao, Luigi Jaramillo, Roz Fanaiayan, Mardieh Dennis, and Karen Hardee. 2016. "Scaling Up Family Planning in Zambia - Part 1: Assessment and Feasibility of Maintaining and Innovative Program," Research Report. Washington, DC: Population Council, The Evidence Project.

(C) 2016 The Population Council, Inc. 


\section{Table of Contents}

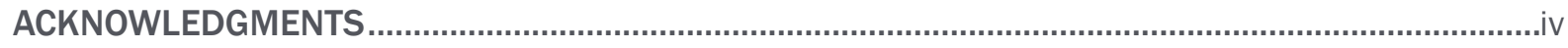

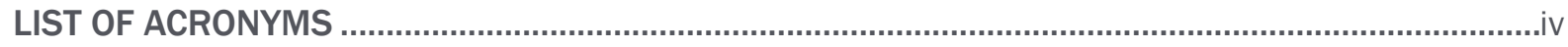

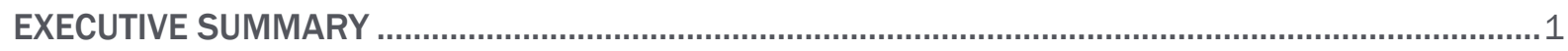

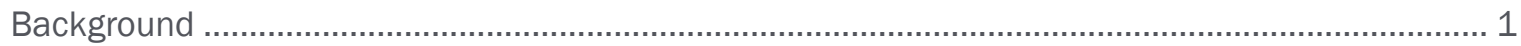

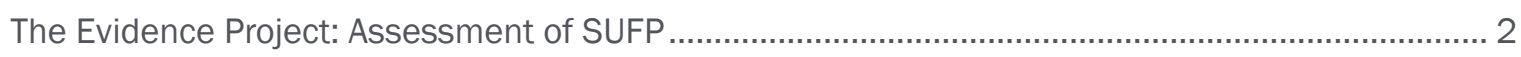

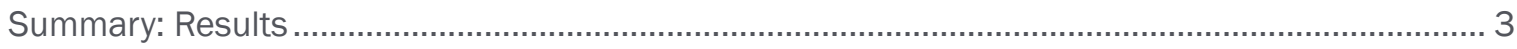

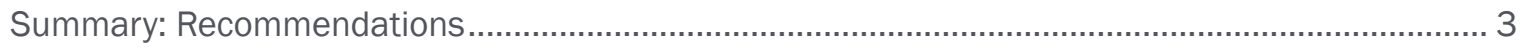

INTRODUCTION

Zambia's Pledge at the 2012 London Family Planning Summit and National Scale Up Plan........... 6

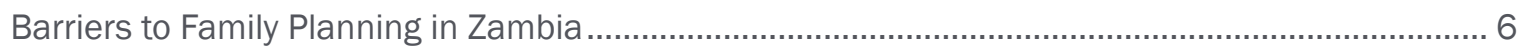

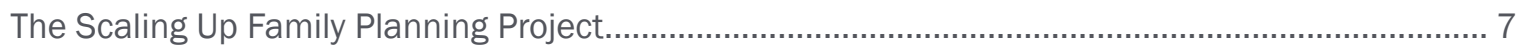

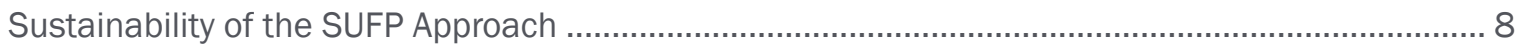

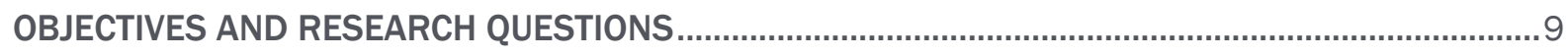

METHODS

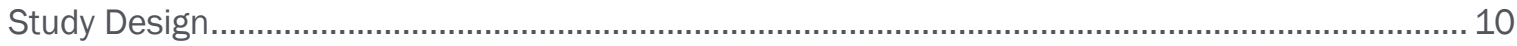

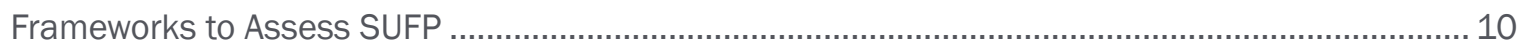

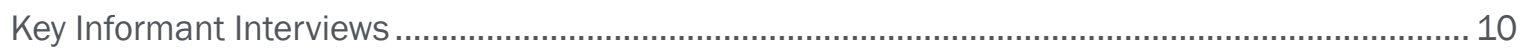

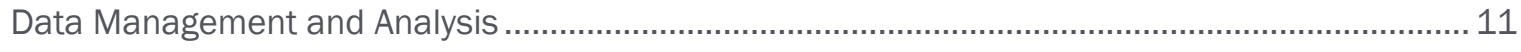

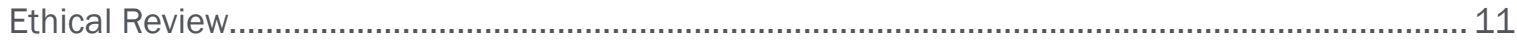

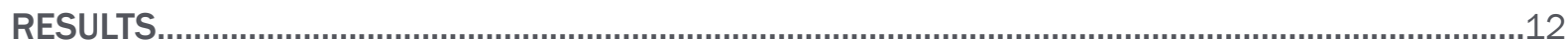

SUFP Through the Lens of the ExpandNet Framework .................................................................. 12

Contribution of SUFP to the Health System and Recommendations for Future Scale Up .............. 17

Potential Challenges with the Transition of SUFP from Project to Program .....................................2 29

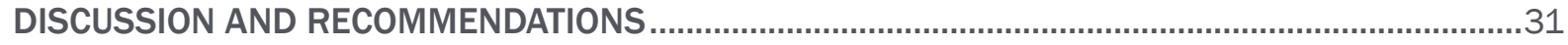

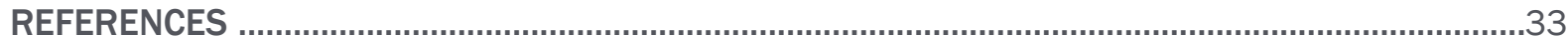

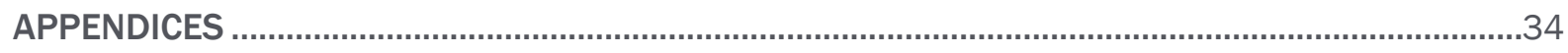

Appendix 1: Key Informant Interview Guide (District, Facility, and Community Level) .....................34

Appendix 2: Stakeholder Discussion Guide (National Level) ......................................................... 38

Appendix 3: Thematic Guide for Analysis of Key Informant Interviews .......................................... 41 


\section{Acknowledgments}

The authors would like to thank Christopher Mazimba, Maurice Pengele, Chisupa Mulenga Goliath and Atanasius Hamwaka of the SUFP Project for the open and collegial engagement throughout study implementation. Additionally, we would like to thank Steve Sampa and Mabumba Chilufya, the District Outreach Coordinators in Kasama and Katete Districts. And thanks to Francoise Armand, from the SUFP Project at the Abt Associates office in the USA for bringing a helpful high-level perspective on SUFP implementation during the study.

We kindly thank Loyce Munthali of USAID in Lusaka; Mihira Karra and Erika Martin of USAID, Washington, DC; Uzoamaka Gilpin of DfID in Lusaka; and Dyness Kaluba, Chisha Mwiche, Trust Mufune and other colleagues of the MCDMCH.

Our appreciation also goes to David Collins and Colin Gilmartin at Management Sciences for Health for a collaborative effort in documenting the SUFP project, and for bringing a warmth to the costing analysis of SUFP.

\section{List of Acronyms}

CBD Community based distributor

CPR Contraceptive Prevalence Rate

CSO Central Statistics Office

DHS Demographic and Health Survey

ERES Excellence in Research Ethics and Science (Zambia human subjects review board)

FP Family planning

IUD Intrauterine devices

LARC Long acting reversible contraceptives

MCDMCH Ministry of Community Development and Mother Child Health (former)

mCPR Modern Contraceptive Prevalence Rate

MIS Management Information System

$\mathrm{MOH} \quad$ Ministry of Health

NGO Non-governmental organization

RH Reproductive Health

SUFP Scaling Up Family Planning

UNFPA United Nations Population Fund

WHO World Health Organization 


\section{Executive Summary}

\section{BACKGROUND}

At the 2012 London Summit on Family Planning, and in a subsequent eight-year scale up plan, Zambia made a commitment to increase its contraceptive prevalence rate (CPR) to 58 percent by 2020, through a mix of policy and programmatic approaches. In addition to increasing domestic funding and partnerships with donors and strengthening the supply chain for commodities, Zambia pledged to expand method mix and increase access to family planning (FP), particularly for underserved populations, through the use of community-based distributors (CBDs) to increase demand among women, men and communities.

With a mCPR of 45 percent in 2014, the country needs to accelerate scale up in order to meet the contraceptive needs of women and couples and to achieve its goal of 58 percent mCPR.

A number of supply-side barriers limit family planning provision, particularly of LARCs, including a shortage of trained staff and lack of needed equipment, commodities and consumables (MCDMCH, 2013). At the health center level, stock outs are more frequent than at higher levels, due to inadequate transport of supplies and delays in submitting requisition orders at facility and district levels. Additionally, although FP is free at public sector facilities, the limited method mix in the public sector constrains contraceptive choice, and price remains a barrier in the private sector. Distance is often a barrier for those living in rural areas, especially during the rainy season when travel time to a health facility averages two hours. Scheduling of services can also serve as a barrier for FP access, especially when the hours are limited and services are not coordinated with the provision of other related services that women attend. Lastly, inadequate infrastructure may limit a woman's privacy and comfort in accessing FP services.

Demand-side barriers to the adoption of FP also inhibit use, including actual or feared partner/spousal disapproval, social stigma, myths, rumors and misinformation about FP generally and about specific methods, fear of side effects, and health concerns. Some methods, notably LARCs other than injectables, suffer from negative myths and false beliefs. For example, some believe that implants and IUDs can travel around the body and become lodged in the brain, the heart, or a growing fetus, or that fertility will not return after LARC removal. Some health providers, too, reportedly share these negative beliefs and then act to deter client's interest in contraceptive use.

Adolescent fertility in Zambia is a concern. The country has one of the highest adolescent fertility rates in sub-Saharan Africa (CSO et al., 2014). 29 percent of teenage girls ages 15-19 have begun child bearing. Limited access to FP, particularly among young women, is evident in the large number of young women receiving post-abortion care services in Zambia. For instance, in 2010, 90 percent of the 90,000 women who received post-abortion care in Zambia were under the age of 20 (MCDMCH, 2013).

To support the Government of Zambia in addressing its reproductive health challenges and in meeting its goals for 2020, the United Kingdom Department for International Development (DfID) funded a fouryear effort to support public sector contraceptive expansion under the Scaling Up Family Planning (SUFP) Project, led by Abt Associates. Launched in 2012, and with a focus on hard-to-reach areas and youth and expanding access to LARCs, SUFP was a technical assistance program designed to strengthen the ability of the public sector to provide services to meet the country's FP2020 goals. SUFP focused on several aspects of integrating FP outreach and service delivery into the government health system and in supporting out- 
reach into communities to increase demand for FP and to address myths and misconceptions. These included capacity building, infrastructure strengthening, behavior change communication, contraceptive security, policy and advocacy in support of an enabling environment for reproductive health and FP, supply chain management, and strengthening management information systems (MIS).

Given the progress under SUFP in strengthening provision of FP at the district level and linking facility- and community-based programming, it is important to assess the process of scaling up and the feasibility of the government continuing implementation of the scaled up services after the end of the project. Furthermore, for the government to consider continuation of the elements of the SUFP approach, it is important to have an idea of the costs of the approach. Given the attention to scaling up in FP, lessons from the SUFP experience of scaling up through strengthening the public sector health system and adding an innovative approach to outreach (the Camping Approach) are also important for other countries.

\section{THE EVIDENCE PROJECT: ASSESSMENT OF SUFP}

This assessment of the process of scale up under the SUFP Project and the feasibility of continuation by the Government of Zambia is Part 2 of a broader implementation research study that also includes a costing study of the SUFP approach. These paired studies were designed to establish the feasibility of integrating successful interventions and lessons from the SUFP project into Zambia's health system at the conclusion of the project and to contribute to global learning on the scale up of family planning. Since the SUFP Project was in its final year when the study was undertaken, the study was largely a retrospective analysis.

At the outset, the study focused on just one innovation within the SUFP, the Camping Approach. It was quickly realized that singling out only one component of the SUFP was not useful, thus the objective of the study was broadened to focus on the combined elements of the SUFP. The revised objectives of this research were to:

1. Provide recommendations regarding the feasibility of integrating the SUFP approach into Zambia's public sector family planning system at the conclusion of the SUFP project in 2016

2. Explore the fidelity and adaptation of the SUFP approach during its scale up process

3. Identify barriers and facilitators to scale up

4. Better understand the cost implications in determining the scope and pace of scale up

5. Contribute to global learning on scale up of family planning programs

This report focuses on objectives 1-3 and 5. See Part 2 (Collins et al., 2016) for results related to objective 4 on costing.

This component of the broader study adopted a qualitative approach to assessing the scale up process and feasibility of continuation under the government health system after the end of the project. The study comprised key informant interviews with a range of stakeholders, guided by two frameworks for scale up and health systems strengthening, namely, the ExpandNet WHO Framework and the WHO Health Systems Framework. A total of 40 key informant interviews (KIIs) were conducted with stakeholders at the national, district, and community levels in Lusaka, Kasama, and Katete districts. These sites were selected to represent experiences at the national policymaker level (Lusaka) and in year 1 pilot (Kasama) and year 2 expansion (Katete) SUFP implementation districts. Key stakeholders included senior management in the SUFP project, the district level project and Ministry of Health $(\mathrm{MOH})$ staff, facility providers, and community-based distributors (CBDs). KIIs were undertaken to solicit insights and perceptions of the scale up process and explore future potential to continue the SUFP approach in the public sector. 


\section{SUMMARY: RESULTS}

Rather than scale up a new innovation, the core approach of SUFP was to work within the existing health system and family planning program to strengthen supply of and demand for family planning. SUFP did not provide FP services, but focused on improving demand for and supply of services provided by the public sector. SUFP focused on several important aspects of decentralizing and integrating FP service delivery into the public sector health system at district, facility, and community levels, with an emphasis on reaching poor and underserved women and adolescents.

The findings from the qualitative assessment show that respondents had a positive view of the contribution of SUFP and its engagement with the health system in Zambia. SUFP has been successful in scaling up increased access to FP commodities and services in the 26 districts reached under the project and emphasizing the importance of FP within the selected communities. This report highlights the respondents' perceptions of the implementation of the overall SUFP program, including the Camping Approach, and their suggestions for moving the approach forward at the close of the project. While SUFP was widely viewed by respondents as successful in expanding access to FP and in strengthening services, they noted barriers to FP service delivery that generalize beyond SUFP and remain features of the health system that policymakers, researchers, and service providers need to be aware of when working to scale up family planning services.

Together with the Part 2 of the study (Collins et al., 2016), these recommendations provide vital information for the government and donors to develop programming to continue the advances made under SUFP and to expand the approach to reach more districts in order to reach the country's FP2020 goal. Recommendations from respondents are organized under the themes of the six health systems building blocks, and demand.

\section{SUMMARY: RECOMMENDATIONS}

\section{Leadership/Governance}

- Improve communication between NGOs and the government at district and sub-district levels to increase awareness of each organization's involvement in important activities. Better communication will also help improve accountability for NGOs and the government.

- Hire a full-time FP Coordinator to oversee the FP activities for each district. The presence of a coordinator who is committed completely to FP will allow adequate attention to the FP issues that facilities and communities face on a daily basis.

- Encourage political buy-in for FP at the national level to ensure pressing FP issues (e.g. financing, quality of care, broad method mix at outpatient facilities) are not overlooked or neglected.

\section{Financing}

- Funds should be earmarked for FP activities, distinct from general MCDMCH grants. If FP is budgeted separately from maternal and child health, there may be better planning of outreach activities.

- Efforts to continue utilization and to improve the efficiency and effectiveness of the SUFP strategy would benefit from partnering with other donor supported initiatives. Funding can be sustained and outreach costs can be reduced by coordinating with other donor agencies, as well as integrating FP and the Camping Approach with other outreach and mobilization activities.

\section{Workforce}

- Train more $\mathrm{CBDs}$ and providers to ensure that there are enough staff members to address the 
increasing demand for FP services (at least one CBD per neighborhood). Increasing the number of trained personnel will improve the opportunities for clients to receive high quality care.

- Offer refresher training courses for employees to support employees in their line of work. Refresher courses will help CBDs and providers feel confident in themselves and with the information they impart to their clients.

- Compensate CBDs for their time and valuable work. Respondents have mentioned CBDs quitting due to lack of compensation; compensation can financially incentivize CBDs to stay accountable and motivated.

- Supervise and evaluate staff members to ensure that accurate and suitable information is shared with clients. Supervision and evaluation will also keep employees accountable for their attitudes and for delivering high quality care. Designated supervisors should be appointed, rather than relying on a rotation of nurses to fill these positions.

\section{Health Information Systems}

- Submit reports on time to help inform the district of the commodities that are low before the facility is stocked out.

- Look for and adopt technologies to enhance the Health Information System to capture data more accurately and quickly.

\section{Access to FP Commodities}

- The government should identify strategies that improve method mix at lower level facilities, including the introduction of new FP methods, to improve client satisfaction levels. With a greater variety of methods, clients will be able to choose the method most comfortable to them.

- Educate CBDs on how to stock commodities to reduce the number of stock outs in the facility and community.

- Ensure that the government is delivering sufficient commodities to the facilities, so that clients always have their preferred method available to them.

\section{Service Delivery}

- Increase availability of infrastructure to comfortably provide FP services to clients. Oftentimes clients are shy to access FP services; building new space or designating current space specifically for FP provision will help clients feel more comfortable accessing these services.

- Increase financial support for camping and outreach to reach clients in rural areas (at least K50 for CBDs and K100 for providers).

- Many clients depend on outreach activities, but currently CBDs lack the necessary transportation to reach clients. This issue may be improved by providing more than one bicycle per facility catchment area.

- Integrate FP activities with other services to reduce costs and increase opportunities for clients to access services.

- Make the Camping Approach specific to each district to ensure adequate use of funds. Some techniques may not be successful in every district, so it's important to know the strengths and weaknesses of each district. 


\section{Demand}

- Continue sensitizing the community to correct misunderstandings, educating the community and keeping demand levels high. Clients may forget what they are taught, so it's important to continue sensitizing the community and reinforcing the importance of FP.

Overall, SUFP provided technical assistance to strengthen community-based and health facility provision of FP counseling and methods. By basing the intervention at the district level and strengthening the district's capacity to manage family planning, and by improving the capacity of providers in health facilities to deliver services and the capacity of outreach workers to engage in social and behavior change communication (SBCC) in the community, SUFP worked to address both supply and demand barriers to FP service delivery. 


\section{Introduction}

\section{ZAMBIA'S PLEDGE AT THE 2012 LONDON FAMILY PLANNING SUMMIT AND NATIONAL SCALE UP PLAN}

At the 2012 London Summit on Family Planning, and in a subsequent eight-year scale up plan, Family Planning Services: Integrated Family Planning Scale Up Plan 2013-2020, Zambia made a commitment to increase its contraceptive prevalence rate (CPR) to 58 percent by 2020, through a mix of policy and programmatic initiatives (http://www.familyplanning2020.org/entities/150; MCDMCH, 2013). In addition to increasing domestic funding and partnerships with donors and strengthening the supply chain for commodities, Zambia pledged to expand method mix and increase access to family planning (FP), particularly for underserved populations, through use of CBDs to increase demand among women, men and communities.

Zambia's pledge in 2012 and the national scale up plan are intended to improve reproductive health outcomes in the country. The scale up plan has as its main objectives to increase access to FP services and reduce the maternal mortality ratio from 591 deaths per 100,000 live births in 2007 to 159 deaths per 100,000 live births by 2020; to increase the modern contraceptive prevalence rate (mCPR) from 31.7 percent in 2007 to 58 percent by 2020; to reduce unmet need for contraception from 27 percent in 2007 to 14 percent by 2020; and to reduce teenage pregnancy from 28 percent in 2007 to 18 percent by 2020 (MCDMCH, 2013).

\section{BARRIERS TO FAMILY PLANNING IN ZAMBIA}

While the 2013-14 DHS showed an mCPR of 45 percent, the country still has to accelerate scale up in order to meet the contraceptive needs of women and couples, and to achieve its goal of 58 percent mCPR. Unmet need for family planning stands at 21 percent, mostly for spacing (14 percent). Among modern methods, use of the injectable is highest (19 percent), followed by the pill (12 percent), implants ( 6 percent), and the male condom (4 percent). Knowledge and use of some long acting and reversible contraception (LARC) (injectables, IUDs, and implants) are low and access to these methods is uneven in the country, particularly in rural and underserved areas.

A number of supply-side barriers limit family planning provision, particularly LARC, including a shortage of trained staff and lack of needed equipment, commodities and consumables (MCDMCH, 2013). At the health center level, stock outs are more frequent than at higher levels, due to inadequate transport of supplies and delays in submitting requisition orders at facility and district levels. Additionally, although FP is free at public sector facilities, the limited method mix in the public sector constrains contraceptive choice, and price remains a barrier in the private sector. Distance is often a barrier for those living in rural areas, especially during the rainy season, when travel time to a health facility averages two hours. Scheduling of services can also serve as a barrier to FP access, especially when the hours are limited and services are not coordinated with the provision of other related services that women attend. Lastly, inadequate infrastructure may limit a woman's privacy and comfort in accessing FP services.

Demand-side barriers to adoption of FP also inhibit use, including actual or feared partner/spousal disapproval, social stigma, myths, rumors and misinformation about FP generally and specific methods, fear of side effects, and health concerns. Some methods, notably LARC other than injectables, suffer from negative myths and false beliefs. For example, some believe that implants and IUDs can travel around the body and become lodged in the brain, the heart or a growing fetus, or that fertility will not return after LARC removal 
(MCDMCH, 2013). Some health providers, too, reportedly share these negative beliefs and then act to deter client's interest in contraceptive use.

Adolescent fertility in Zambia is a concern. The country has one of the highest adolescent fertility rates in sub-Saharan Africa (CSO et al., 2014). 29 percent of teenage girls ages 15-19 have begun child bearing. Limited access to FP, particularly among young women, is evident in the large number of young women receiving post-abortion care services in Zambia. For instance, in 2010, 90 percent of the 90,000 women who received post-abortion care in Zambia were under the age of 20 (MCDMCH, 2013).

\section{THE SCALING UP FAMILY PLANNING PROJECT}

Among other donor inputs, to support the Government of Zambia in addressing its reproductive health challenges and in meeting its goals for the year 2020, the United Kingdom Department for International Development (DfID) funded a four-year effort to support public sector contraceptive expansion under the Scaling Up Family Planning (SUFP) Project, led by Abt Associates. Launched in 2012, and with a focus on hard to reach areas, youth, and expanding access to (LARC), SUFP was a technical assistance program to strengthen the ability of the public sector to provide services to meet the country's FP2020 goals. SUFP focused on several aspects of integrating FP outreach and service delivery into the government health system and in supporting outreach into communities to increase demand for family planning and to address myths and misconceptions. These included capacity building, infrastructure strengthening, behavior change communication, contraceptive security, policy and advocacy in support of an enabling environment for reproductive health and FP, supply chain management, and strengthening management information systems.

Reports on progress under SUFP showed that project activities were successful in scaling up FP in one-quarter of the county's districts (26 out of 105 districts). Collins et al. (2016: 34) found that:

"The analysis of SUFP and MCDMCH data indicates that the implementation of the
scaling-up package of activities in the districts and the replication across districts
were successful and also that gains made were largely maintained through the end of
the project. The interventions appear to have contributed to increases in numbers of
family planning clients in general and in LARCS in particular, resulting in major
increases in CYP. While the initial training, demand creation and strengthened
outreach interventions are likely to have played a major role in the positive results
achieved, it is also important to recognize the role of the project in supporting the
districts in terms of managerial and financial support provided for outreach and
supervision and also for improving commodity supply logistics."




\section{SUSTAINABILITY OF THE SUFP APPROACH}

Given the progress under SUFP in strengthening provision of FP at the district level and linking facility- and community-based programming, it is important to assess the process of scaling up and the feasibility of the government continuing implementation of the scaled up services after the end of the project. Furthermore, for the government to consider continuation of the elements of the SUFP approach, it is important to have an idea of the costs of the approach. Given the attention to scaling up in FP, lessons from the SUFP experience of scaling up through strengthening the public sector health system and adding an innovative approach to outreach (the Camping Approach) are also important for other countries. 


\section{Objectives and Research Questions}

This assessment of the process of scale up under the SUFP Project and the feasibility of continuation by the Government of Zambia is Part 1 of a broader implementation research study that also includes a costing study of the SUFP approach (Collins et al., 2016). These paired studies were designed to establish the feasibility of integrating successful interventions and lessons from the SUFP project into Zambia's health system at the conclusion of the project, and to contribute to global learning on the scale up of family planning. Since the SUFP Project was in its final year when the study was undertaken, the study was largely a retrospective analysis.

At the outset, the study focused on just one innovation within the SUFP, the Camping Approach. It was quickly realized that singling out only one component of the SUFP was not useful, thus the objective of the study was broadened to focus on the combined elements of the SUFP. The revised objectives of this research were to:

1. Provide recommendations regarding the feasibility of integrating the SUFP approach into Zambia's public sector family planning system at the conclusion of the SUFP project in 2016

2. Explore fidelity and adaptation of the SUFP approach during its scale up process

3. Identify barriers and facilitators to scale up

4. Better understand the cost implications in determining the scope and pace of scale up

5. Contribute to the global learning on scale up of family planning programs

This report focuses on objectives 1-3 and 5. See Part 2 (Collins et al., 2016) for results related to objective 4 on costing. 


\section{Methods}

\section{STUDY DESIGN}

This component of the broader study adopted a qualitative approach to assessing the scale up process and feasibility of continuation under the government health system after the end of the project. In addition to a review of program documents, the study comprised key informant interviews with a range of stakeholders.

\section{FRAMEWORKS TO ASSESS SUFP}

Design and implementation of this study was guided by two frameworks for scale up and health systems strengthening, namely, the ExpandNet WHO Framework and the WHO Health Systems Framework.

To assess the scale up approach, the study adopted the ExpandNet Framework (http://www.expandnet.net), a widely used model to guide scale up processes and to evaluate scale up (Lundgren et al., 2012; Hainsworth et al, 2014; Keyonzo, et al., 2015; Huaynoca). The ExpandNet framework consists of five elements of scale up and offers tools for describing and documenting the actual scale up process (Simmons, 2010). The innovation refers to the intervention that is being scaled up. The user organizations are those that seek to or are expected to adopt and implement the innovation on a large scale. The environment includes those conditions and institutions that affect the prospects for scaling up. The resource team consists of the major actors who promote and facilitate wider use of the innovation. Lastly, the scaling-up strategy refers to the plans and actions necessary to fully establish the program in service delivery. By focusing on these contextual and logistical elements, the study provides key insights into the scale up process that can be used to guide the assessment of environmental influences on scale up the cost and resource mobilization, in addition to monitoring and evaluation.

In addition, since the SUFP approach to scale up focused on strengthening the health system's capacity to provide family planning, the study has also integrated the WHO Health Systems Framework (WHO, 2007) to assess how the six building blocks in WHO's framework were affected through the project. This framework is built on the idea that a health system can be analyzed in its totality by using six building blocks: leadership/ governance, healthcare financing, health workforce, medical products/technologies, information and research, and service delivery (World Health Organization, 2010). Leadership/governance ensures the existence of strategic policy frameworks in addition to effective oversight, coalition-building, and accountability. Healthcare financing raises adequate funds to ensure people can use needed services and are protected from financial catastrophe. Health workforce refers to sufficient numbers and mix of staff that are competent, responsive and productive. Medical products/technologies ensure equitable access to medical products that are safe, high quality and effective. A health information system is one that ensures the production, analysis and dissemination of reliable information on health performance. Service delivery refers to services delivered effectively, safely and with high quality to those in need. Using this framework, researchers will be able to report respondents' view on how SUFP addressed the components of FP integration within the health system.

These two frameworks guided the design of the key informant interview guide (see Appendix 1 and 2).

\section{KEY INFOR MANT INTERVIEWS}

A total of 40 key informant interviews (KIIs) were conducted with stakeholders at the national, district and community levels in Lusaka, Kasama and Katete districts (see Table 1). These sites were selected to represent 
TABLE 1 | KEY INFORMANT INTERVIEWS

\begin{tabular}{|c|c|}
\hline TYPE OF KEY INFORMANT & NUMBER \\
\hline National and project representatives & 2 \\
\hline District-level SUFP and MOH staff & 10 \\
\hline Facility providers & 12 \\
\hline Community-based distributors & 16 \\
\hline TOTAL & 40 \\
\hline
\end{tabular}

experiences at the national policymaker level (Lusaka) and in year 1 pilot (Kasama) and year 2 expansion (Katete) SUFP implementation districts. Key stakeholders included senior management in the SUFP project, the district-level project and Ministry of Health $(\mathrm{MOH})$ staff, facility providers, and community-based distributors. KIIs were undertaken to solicit insights and perceptions of the scale up process and explore future potential to continue the SUFP approach in the public sector.

\section{DATA MANAGEMENT AND ANALYSIS}

The KIIs lasted from 30-60 minutes. Interviews were recorded after obtaining written informed consent from the interviewee. The interviews were recorded in either a local language or English and then transcribed into Microsoft Word and translated to English when necessary. The transcribed texts were imported into NVIVO 8 analysis software and analyzed. Following coding, a full list of themes was made available for categorization using a hierarchical framework of emerging main and sub-themes established deductively from the ExpandNet and WHO Health Systems Frameworks (see Appendix 3). The thematic guide was methodically applied to all of the interview transcripts and thematic patterns were evaluated.

Data analysis was reflective and included sharing views with the research team to avoid biased interpretations. The analysis was ongoing throughout the study to facilitate a deeper understanding of issues, and for clarification and subsequent follow up. Preliminary analysis entailed open coding and progressive categorization of issues based on a deductive approach to examine key issues identified at the design stage of the research, and then updated through an inductive approach to examine relevant issues that emerged from the data.

\section{ETHICAL REVIEW}

Ethical approval of the study was granted by the Population Council's Institutional Review Board (p690) and the Zambia review board Excellence in Research Ethics and Science (ERES) (no. 2015-Feb-017). The Zambia Ministry of Health granted authority to conduct the research (MH/101/17/6). 


\section{Results}

\section{SUFP THROUGH THE LENS OF THE EXPANDNET FRAMEWORK}

While SUFP did not use the ExpandNet Framework explicitly in implementation, it is a useful lens to assess the scale up. In this section, we describe SUFP using the 5 elements of that framework: innovation, the user organization, the environment, the resource team and the scaling up strategy.

\section{The Innovation}

Rather than scale up a new innovation, the core approach of SUFP was to work within the existing health system and family planning program to strengthen supply of and demand for family planning (Box 1). SUFP did not provide FP services, but focused on improving demand for and supply of services provided by the public sector. SUFP focused on several important aspects of decentralizing and integrating FP service delivery into the public sector health system at district, facility and community levels, with an emphasis on reaching poor and underserved women and adolescents. Figure 1 shows the Theory of Change for the project.

SUFP provided technical assistance to strengthen community-based and health facility provision of FP counseling and methods. By basing the intervention at the district level and strengthening the district's capacity to manage family planning, and by improving the capacity of providers in health facilities to deliver services and the capacity of outreach workers to engage in social and behavior change communication (SBCC) in the community, SUFP worked to address both supply and demand barriers to family planning.

Respondents noted that the value of SUFP was that it worked within the existing system.

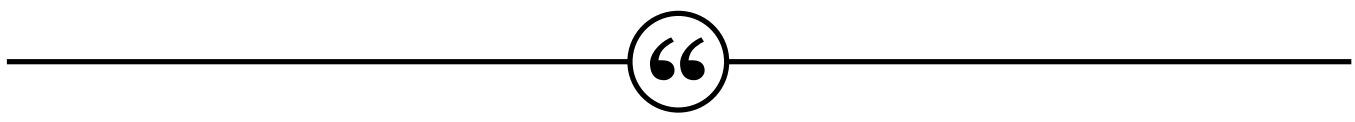

"Four years ago we all met as family planning working technical group and we were thinking what would be the best way to address the issue of FP 2020 [and the discussion showed] that we needed to come up with a national process of scaling up and this is why we have a scale up national plan... because that is not just for SUFP, it is a national program and it means national commitment" -National-level respondent 


\section{FIGURE 1 | THEORY OF CHANGE FOR THE SUFP PROJECT}

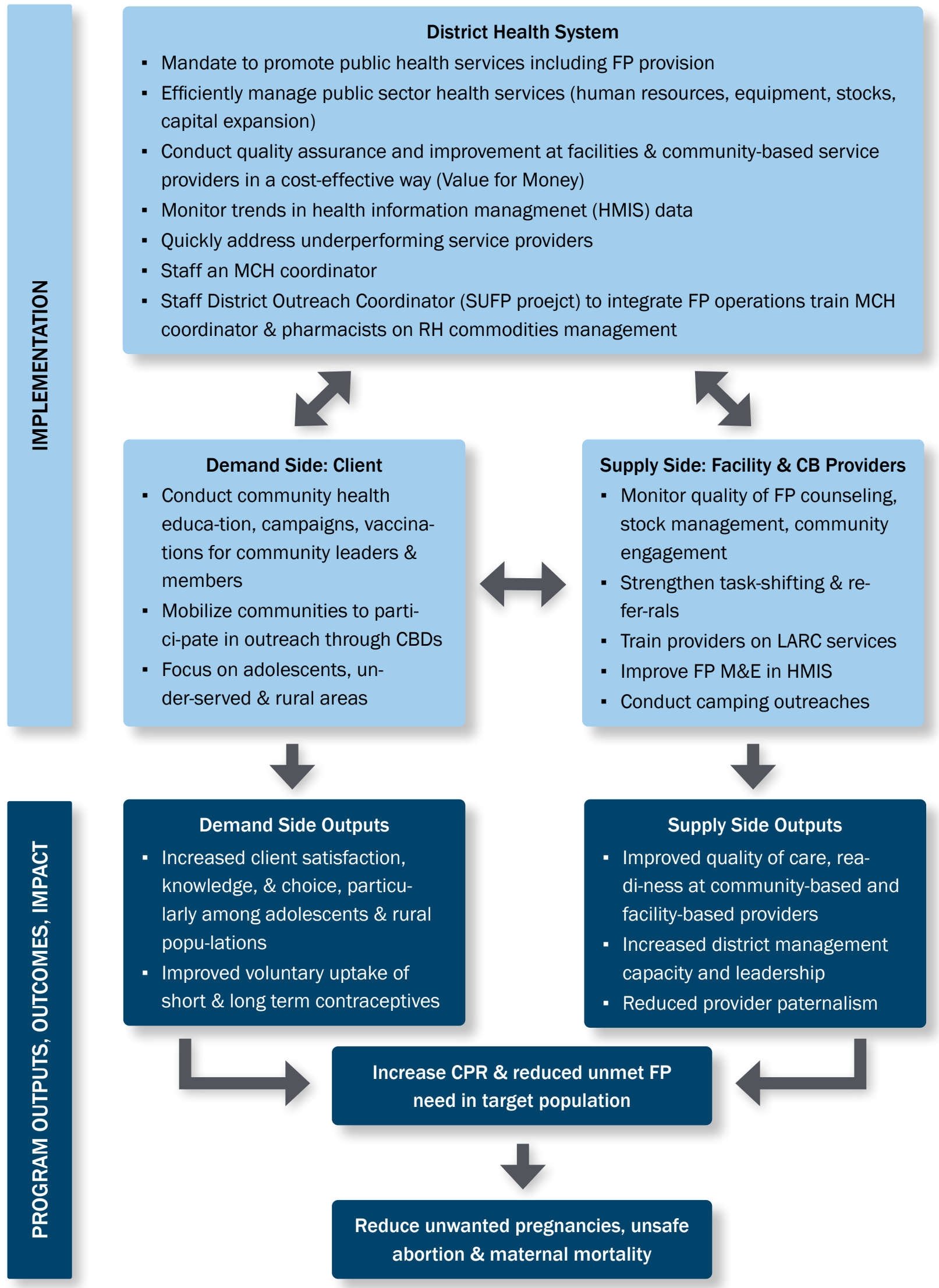




\section{The User Organization}

For SUFP, the user organization included the Ministry of Health, Ministry of Community Development Mother and Child Health (MCDMCH), District Health Management Teams and other service delivery actors involved in the Camping Approach.

\section{Environment}

While there was high level political support for FP, a number of myths and misconceptions about family planning existed at the community level and lack of support from community and religious leaders affected demand for and use of FP services. SUFP addressed this environment for family planning by engaging with the community to address myths and misconceptions about contraceptives, being cognizant of cultural beliefs and utilizing the Camping Approach to reduce economic and geographic barriers for residents in rural areas.

\section{Resource Team}

The resource team for implementation of SUFP included the SUFP Coordinator, the district FP Outreach Coordinator, the SUFP-trained providers and CBDs, and other NGOs contributing to FP who promote and facilitate wider use of the goals of the comprehensive SUFP program.

\section{Scale Up Strategy}

SUFP's strategy for scaling up included both vertical integration through strengthening relevant functions of the health system to support provision of family planning, including the provision of previously neglected LARC, and horizontal scale up through a phased approach across districts. Based on an assessment that the district level did not have strong capacity for management of family planning, SUFP started in 2012 by placing an FP Coordinator with the district health management team in seven districts, identified by their high unmet need for contraception and low $\mathrm{mCPR}$. The following year, the program expanded to an additional six districts and, in 2014, added 13 more districts for a total of 26 by the project close in 2016.

When asked how they perceived the scale up, respondents gave a range of responses; to most it meant horizontal spread of family planning services to more people, reaching hard to reach populations, expanding the range of services offered and improving the services.

"FPP] is taken or provided to areas where it was not accessed."
-District-level respondent
"Scaling up is the provision of services that are not provided."
-District-level respondent
"S Scaling up means] reaching every women in need."
-Facility-level respondent


In their definition, a few respondents noted the vertical aspect of scaling up — that is, institutionalizing the innovation in the health system.

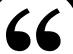

"Scaling up, for me the government was already doing something...but their capacity was not enough."

-District-level respondent

When asked specifically about how SUFP engaged with the health system (reported below), respondents more often reflected on vertical scale up.

SUFP worked to strengthen service delivery at three levels: health facilities, with a focus on their ability to provide LARC, in order to expand method choice; facility outreach on a periodic basis to offer long term methods in nearby communities; and community-level service provision of short term methods and referrals. SUFP also supported the training and mentoring of public health professionals to deliver comprehensive FP counseling for pills, condoms, injectables, IUDs, implants, and emergency contraception.

Designed to increase demand for FP and address myths and misconceptions in the community, SUFP helped various service delivery groups and actors to plan and provide outreach services in hard-to-reach rural communities by employing an innovative outreach strategy, the Camping Approach, to deliver focused technical support to district managers and FP service providers at facility and community levels. One respondent explained that the original Camping Approach was implemented by SUFP staff and that a "Camping Reloaded" approach shifted the focus to public sector staff at the district level.

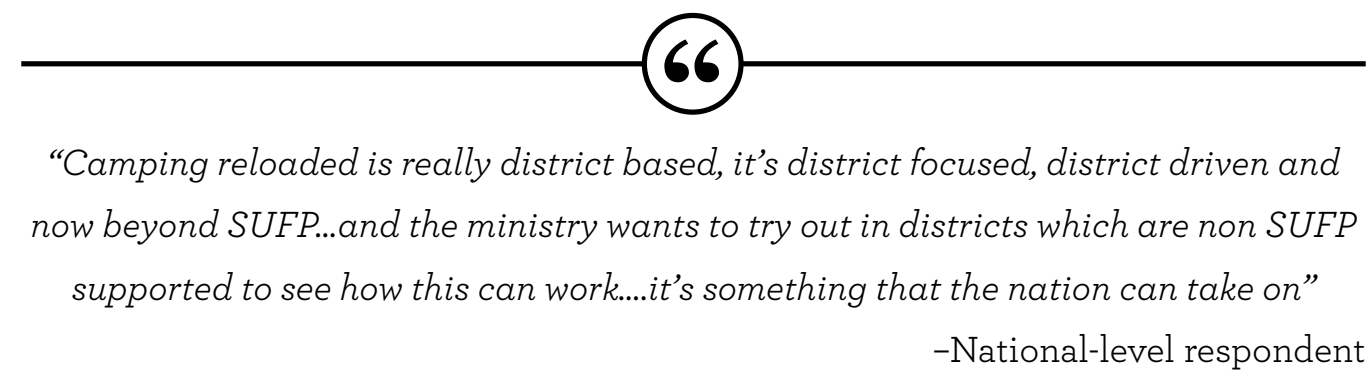

To help the districts coordinate the wide range of demand and supply activities as a single initiative, the twoweek Camping Approach pulled together resources from the district, the targeted facility and neighboring communities to mobilize district resources, engage community leadership, highlight the importance of contraception to community members, launch FP outreach with the available health facility staff, and work with CBDs to ensure that men and women were able to access FP methods.

Engagement in each district varied based on context. In some districts, traditional leadership was the most convincing channel to reach populations. In other districts, religious leaders were highly charismatic and SUFP accordingly engaged them. In each district, the focus was to work intensively and closely with local leaders on FP service uptake through facility, outreach, and community-based service delivery channels. 
Similarly, with supplies and logistics, SUFP combined efforts in each district to ensure that teams doing mobilization, supply chain, and facility staff trainings were synchronized. After the initial two week camping, regular outreach was conducted during shorter periods, ranging from one to a few days, to link facility providers with community-based distributors and leaders engaged in community-based service provision and referral.

Virtually all of the respondents had heard of the Camping Approach, although some knew it as outreach rather than camping. They were positive about the approach, saying that it helped sensitize community leaders to FP and that it addressed myths and misconceptions about FP and allowed more clients to access services.

Respondents also appreciated that the Camping Approach was also integrated into the district health system structure.

\section{$(6)$}

"At times we find that our staff in clinic are unable to meet the community and educate the community on family planning services and provide the community, this is because they are so stressed and they are under-staffed, so when you get partners coming in to camp and do the work on our behalf....it is most welcome approach...

[that] really helped reduce teenage pregnancies, unwanted and unplanned pregnancies because they will get access to family planning methods that otherwise could never be accessed normally because the nurse would say I am busy and I know sometimes when people are so pressured they might not answer the clients properly."

-Facility-level provider

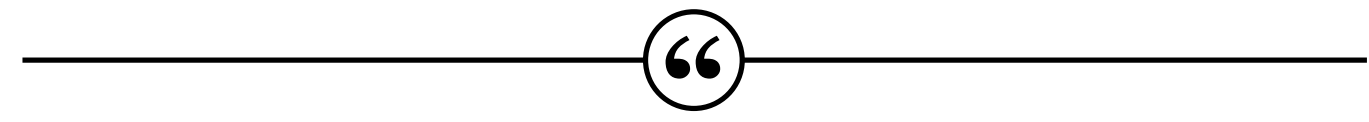

“The use of the existing structures [makes SUFP's Camping Approach different from others] for example, working with the government's workers to do the work, using the community volunteers within the community. I think that would be the biggest difference because some partners have their own employees who go to offer the methods wherever they go and when they come back, if there is no capacity in the government system, it means the work may not continue if they are not there. So I think SUFP's health system strengthening aspect of it is quite crucial." -National-level respondent 


\section{CONTRIBUTION OF SUFP TO THE HEALTH SYSTEM AND RECOMMEN- DATIONS FOR FUTURE SCALE UP}

Overall, respondents had a favorable view of SUFP, and noted a range of contributions from the project, including strengthening the provision of services but also increasing demand through sensitizing communities and clients about FP. Respondents acknowledged the beneficial impact of SUFP on the health system, often citing increased capacity/improved workforce, greater emphasis on FP in leadership and governance, an improved reporting system, greater financial resources for FP, increased provision of services, and a perception that maternal mortality rates may have been reduced.

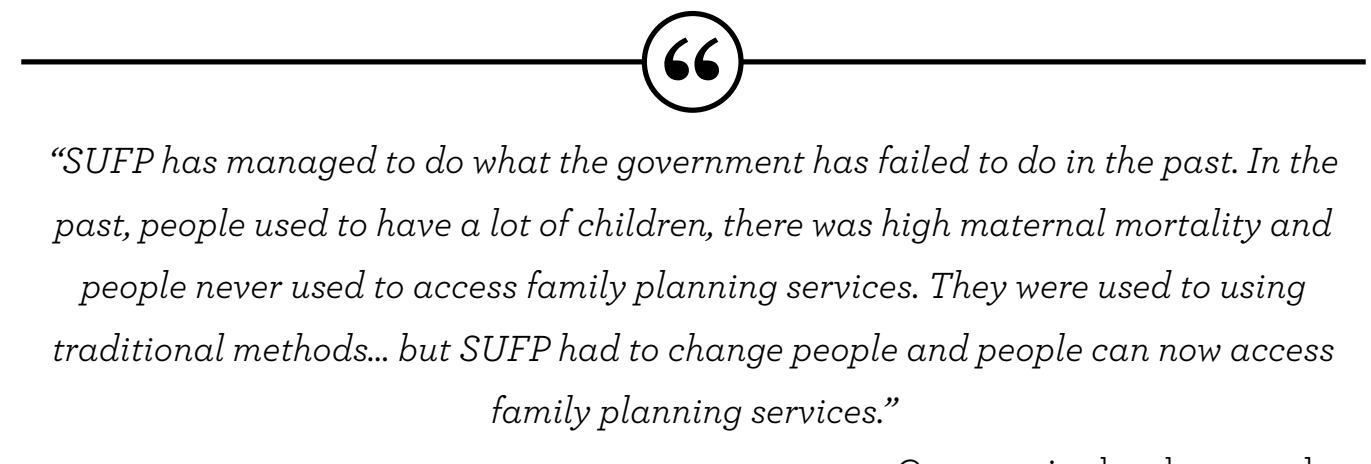

"The programme has provided family planning services to more people than we could have done as a district."

-Facility-level respondent

"They have helped people change from giving birth every year to spacing their

$$
\text { children." }
$$

-Community-level respondent

"Because of these SUFP programs we were managing to reach the unreachable

$$
\text { places." -Community-level respondent }
$$

"It is the training they offered to the staff and it has led people to understand FP

$$
\text { services.” }
$$

$$
\text { -Facility-level respondent }
$$

"We are really thankful for the project, it has really done a lot for us in particular before SUFP I was not trained in long-term FP...I also really feel very proud that I have this skill and we will continue providing the service even when the project maybe has ended."

-Community-level respondent 
WHO's Health Systems Framework is built on the idea that a health system can be analyzed in its totality by using six building blocks: leadership/governance, healthcare financing, health workforce, medical products/ technologies, information and research, and service delivery (WHO, 2015). This assessment shows that SUFP contributed to the health system by engaging in all six of these components.

\section{Leadership/Governance}

With regards to leadership/governance, SUFP has engaged with community leaders as gatekeepers to address misperceptions around contraception and build their support for it. By increasing the level of awareness and importance of FP services at higher levels of leadership, community members are more willing to learn about FP and eager to utilize FP methods.

\section{6}

"It [SUFP] has made most leaders in the district to become aware of the family planning services that are available and the community members have the right to choose which one they want because they have been given information on the methods that they were not privileged to have in the past. Apart from that, the [SUFP] program has helped us realize the importance of family planning. In the past we just used to pay attention to life threatening diseases such as malaria and also cholera... Also family planning has never been among the top ten programs, so when we are dealing with data we take the first ten diseases which each health officer knows and concentrates on and other services like family planning is ranked below the top ten. However, after SUFP came, family planning service provision has become more pronounced."

-District-level respondent

Respondents recommended improving communication between NGOs and the government, and emphasized the need for greater FP presence at a district level (through a FP outreach coordinator) and national level.

"The government and NGOs need to work together and also discuss day-to-day
challenges that each is facing and how they can help each other. I say so because I
have been here for almost a year but I know little about the work of other NGOs."
-District-level respondent
"There is a need to have a FP coordinator because the MCH coordinator does a lot of
things, meaning that some areas will suffer, but if there was specifically person who is
coordinating FP as a whole; her focus will be mainly on FP."

-Facility-level respondent 
"There has to be a good political buy-in right from the top and I know in countries where leadership right from the top has taken issues of family planning seriously it trickles down to service provision in the remotest areas of the country. So we need to have leadership at national level right from the highest position in the country supporting family planning with passion... So apart from the political will we also need to make it a national issue because family planning, as much as it is an issue of the Ministry of Health and Ministry of Community Development and Maternal Child

Health, it is a multi-disciplinary, multi-sectorial issue and can be cross-cutting in various ministries. We are already talking about children's school so we have to bring

in the Ministry of Education inside. We can't talk about family planning without nutrition so we may bring in Agricultural, there are issues of gender so the Ministry of

Gender has to come in. We want the chiefs involved and traditional rulers to understand this issue so we have the Ministry of Tradition and Cultural Affairs to come in so it is indeed a platform that can be discussed across a range and that's why we need to create a very good policy environment."

-National-level respondent

\section{Financing}

Regarding healthcare financing, SUFP introduced additional funds for FP service delivery. It remains to be seen if the greater salience of FP now will result in greater budget allocations from government going forward. Numerous respondents indicated that the SUFP project funds were still inadequate to fully address the need, such as conducting additional outreach or facilitating greater community-based distribution of contraceptives.

Respondents at the district level recommended that funds be set aside specifically for FP, rather than utilizing general MCDMCH grants to fund FP activities.

\section{6}

"There should be a portion [of the grant] to FP interventions countrywide then it will work but if it is that grant which is meant for administrative use of the funds from government, I'm afraid there will be no room to get some money to pay CBDs for their interventions and to buy fuel for outreaches to do camping approaches. I'm afraid it

$$
\text { won't happen." }
$$

-District-level respondent

"We would love to see where funds are just allocated specifically for FP."

-District-level respondent 


\section{Health Workforce}

SUFP has positively affected the health workforce by training CBDs and providers, increasing skill level and knowledge, and improving provider attitudes. Respondents mentioned that SUFP had increased the workforce by training providers in provision of LARCs and CBDs to reduce the workload for staff and improve the quality of offered services. With greater quality of care, interviewees noted an overall reduction of unwanted pregnancies and improved maternal health.

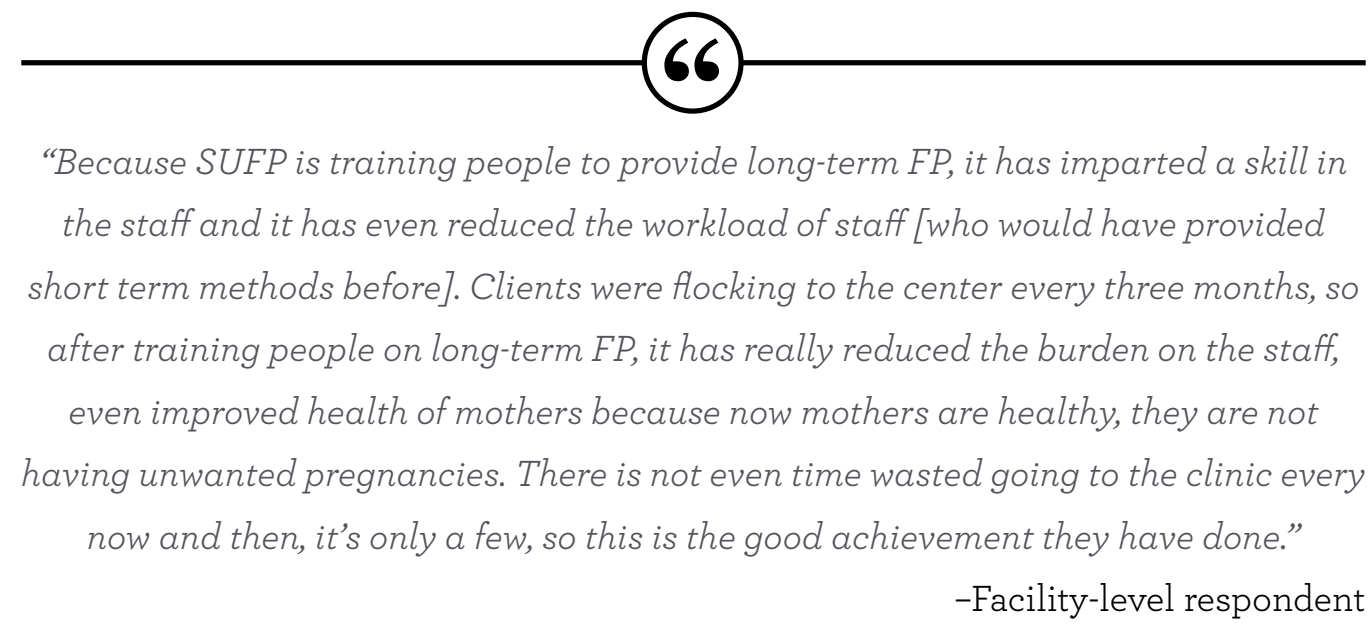

37 of 40 of KII respondents indicated that while SUFP has trained providers, there is still a need for continued training. Interviewees mentioned that illness, position transfers, retirement, death, and termination of positions due to lack of compensation are all contributing factors to community-based and facility-based staff absenteeism and turnover. Furthermore, CBDs, who are volunteers, face pressures at home.

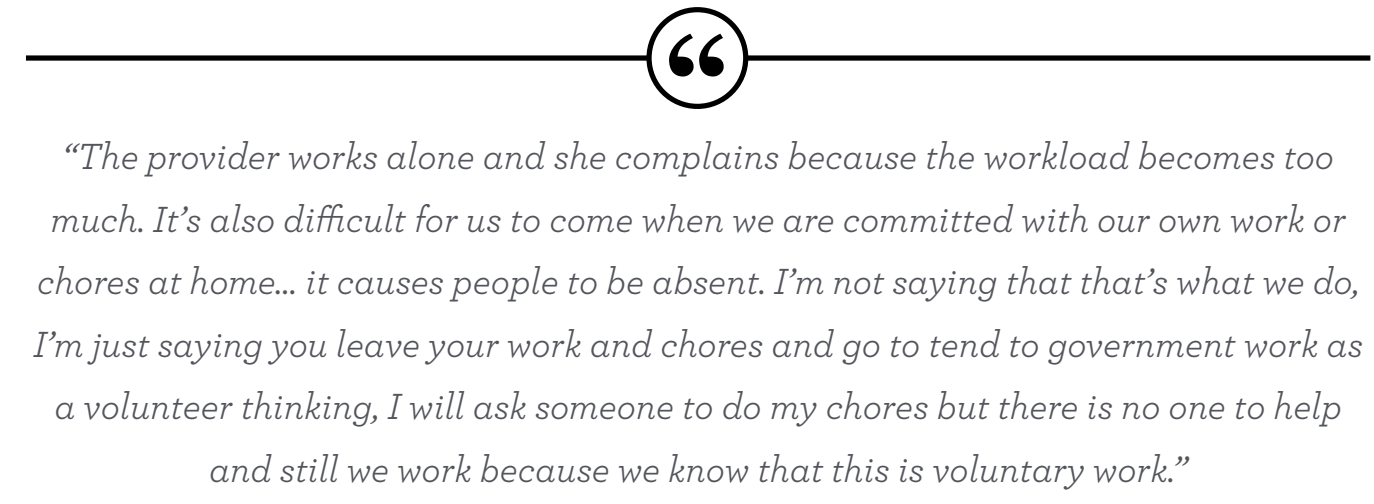

-Community-level respondent

Some respondents reported that staff workers are at times overwhelmed by their workloads, which can compromise the quality of their work and may discourage clients from accessing FP services. 
"As much as SUFP has improved the provision of family planning services, most of these facilities providers are overwhelmed with work because only a few are adequately trained to provide these services."

-Facility-level respondent

"When the [other] staff is not around, you are only one at the clinic, you would compromise the things you do, maybe you will do even short cuts because you would want to attend to a lot of things at the same time, so that also influences the quality of providing FP."

-Facility-level respondent

"Staff turnover and absenteeism becomes a hindrance to work progress because women will come to access FP and find that someone has stopped or is absent. That can cause women to stop coming for FP services because it discourages the women when they want to space their children. If they don't get it [FP services] at that time, in the end she will be pregnant. It's a challenge for the women because if there is no one to provide, then they won't be able to access the FP methods."

-Community-level respondent

"They should put special people in-charge of family planning services at the facility rather than relying on nurses because they are over loaded with work.

-Community-level respondent

Respondents recommended training more health workers, offering refresher training courses, financially motivating workers and evaluating staff members.

\section{6}

"There is need to train more providers and CBDs because there are some service

facilities which do not have a provider nor CBDs, meaning that when SUFP ends, those places will not have access to the services they need."

-Facility-level respondent

"If we can have one CBD at each neighbourhood, we can have one trained or one providing I think we can scale-up FP and even the figures can increase."

-Facility-level respondent 


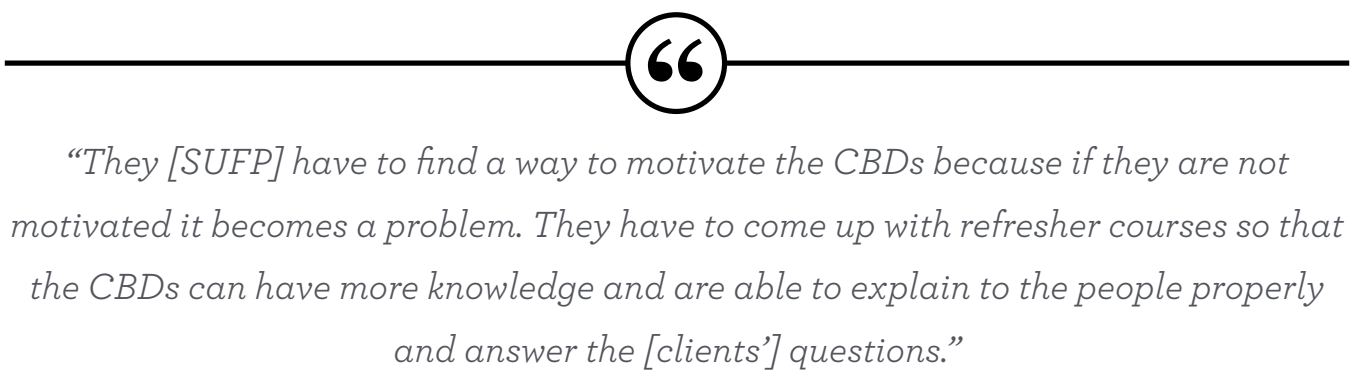

-Community-level respondent

"Supervision can be improved by if they [the leaders] come to check on how the program is being implemented every so often. Even you as a provider you can improve because you know that the leaders are concerned about the program."

-Community-level respondent

\section{Medical Products/Technologies}

Regarding medical products/technologies, respondents were very grateful for SUFP's efforts to limit supply shortages, provide equipment and introduce a new long-term FP method, Jadelle. Respondents observed that SUFP's engagement with the health system has improved supply chain management by following up on reports, providing equipment to store commodities, and preventing stock outs of FP commodities. One of the more frequently mentioned influences of SUFP was the provision of and training on LARC. All these changes have contributed to respondents' perceptions that there is increased access to readily available FP methods at all times.

\section{6}

"The supply chain of FP commodities has changed for those long-term and shortterm. They are readily available at the pharmacy, at the health facility and the CBDs have people that are keeping [the commodities] for their fellow CBDs so that even if the health center is closed the CBD is able to go and collect from a fellow who is within their community twenty-four hours. It [SUFP] has contributed because it provided equipment to store the commodities."

-District-level respondent

"There really was a need because for long-term FP, when you go there, you reduce the number of people coming to the center so congestion has reduced. There are other clients who don't want to travel to the clinic who are shy or maybe busy so when you go there the program is usually successful because it increased access to people who do not want to travel to the clinic."

-Facility-level respondent 
"It changed because a long time ago we used to have very few commodities and at

times we never used to have any, women were being turned back. But after SUFP

came, we have never been out of stock for all the commodities."

-Community-level respondent

Respondents recommended that the government should introduce new types of FP methods into the program; this is understood to mean helping lower level facilities, where more people access services, to stock a broader method mix. Additionally, respondents suggested that stock outs could be limited by educating CBDs to stock commodities and ensuring that the government is delivering sufficient commodities to the facilities.

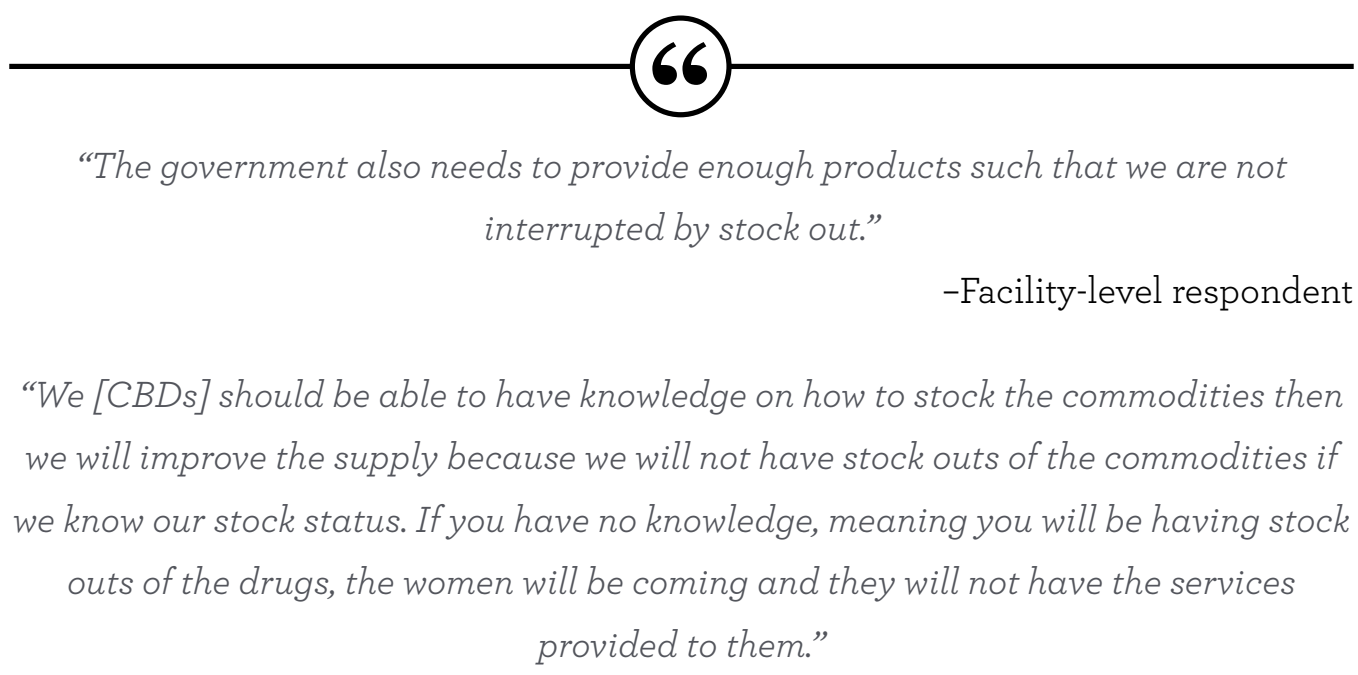

-Facility-level respondent

\section{Health Information Systems}

SUFP also improved the health information and research system by improving reporting and record keeping, whereby staff members better monitor the number of commodities dispensed, the uptake of FP methods over time, and the demographics of clients accessing the services. Respondents stressed the importance of timely submission of the reports and adopting new technologies to strengthen monitoring and evaluation and improve the health information systems. Some facility staff may be more motivated to complete registers if they know that their reports result in timely action.

\footnotetext{
66

"We need to have the new methods and new technologies that can capture data right on site, on time rather than at the end of the day at the clinic where you have to sit and fill in all those registers before you go to sleep and you are extremely exhausted."

-National-level respondent
} 


\section{6}

"The reports need to be submitted on time and they [the district] need to be informed about the rate at which FP commodities are being used so that they can know instead of waiting for the commodities to run out before you inform them."

-Community-level respondent

"The SUFP people were very good because reporting the way we report it, we send the information to them and they make sure they make follow ups. If you are not doing fine, they will make a follow up to come and find out why there has been a reduction maybe in the services that you are offering."

-Facility-level respondent

Some respondents noted the lack of supplies for reporting, including registers.

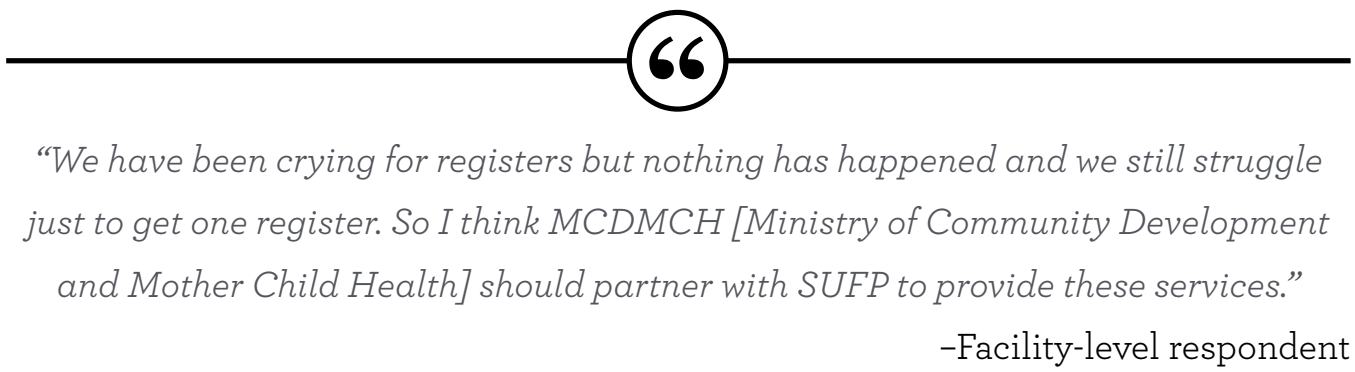

\section{Service Delivery}

With regards to service delivery, SUFP increased the provision of services. SUFP trained CBDs, who created more opportunities to receive FP in the community, and providers, who were trained to administer long-term methods.

Many respondents indicated that lack of space and privacy affected the availability of FP services. When funds are not set aside specifically for FP activities and service delivery is restricted to certain days, service access and quality are negatively affected, and present a supply-side barrier for people seeking to access the services. Additionally, lack of privacy may adversely impact a client's sense of confidentiality and comfort to receive specific procedures.

\section{6}

"The space is not enough so we have allocated Thursday morning as a specific day

to provide family planning services only for (Jadelle). But if we had enough space we could have been providing every day."

-Facility-level respondent 
6

"Some facilities have enough space, especially those in urban areas, but other

facilities do not have enough space and privacy. This makes it very difficult to actually sit down with the women and counsel them, let alone insert an IUD or

$$
\text { Jadelle." }
$$

-District-level respondent

The introduction of SUFP's Camping Approach and facility provider outreach to nearby communities allowed funds to be set aside specifically for family planning. These outreach activities reduced the geographical barriers that clients faced to access FP services, by bringing service providers to the community to offer a broader mix of contraceptives, including long-term methods.

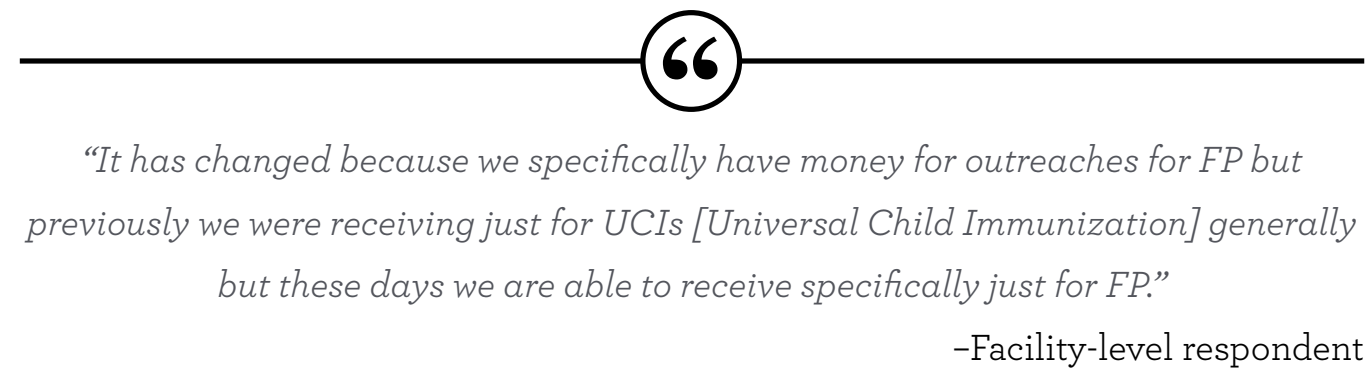

Although grateful for the improvements, interviewees also recognized the introduction of new challenges due to SUFP engagement. Equipment is not always provided in a timely manner. Most importantly, the majority of respondents cited inadequate funding that prevented them from properly implementing the Camping Approach.

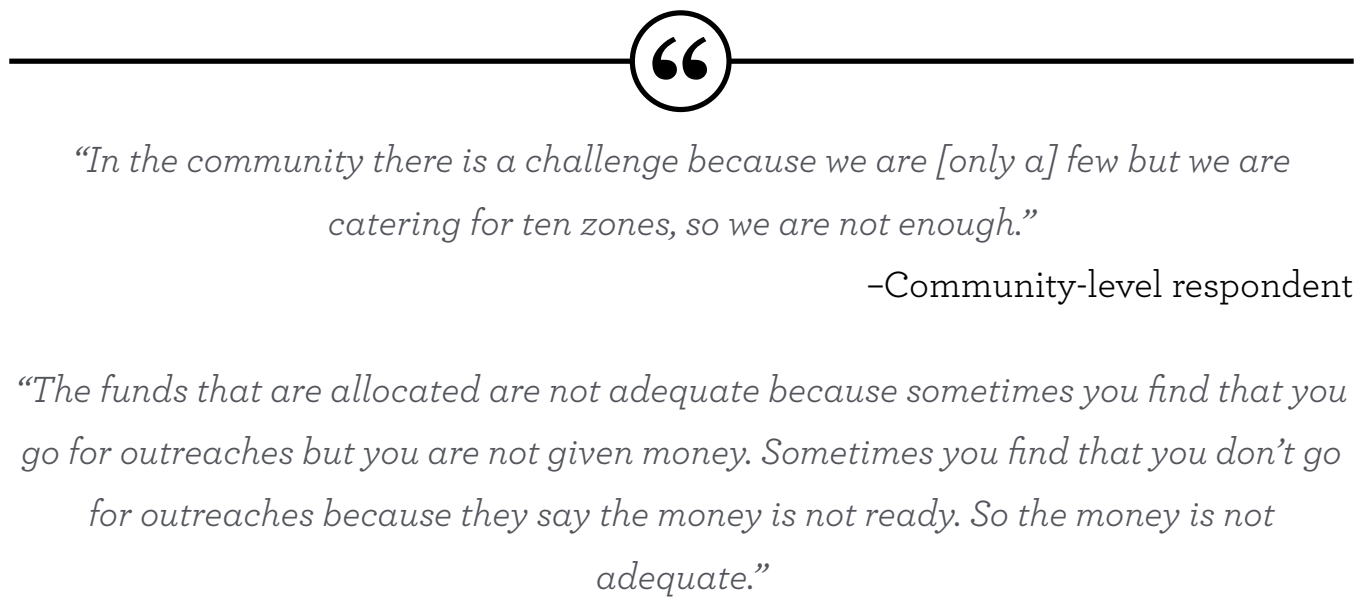

-Community-level respondent

Respondents recommended that there should be more infrastructure or dedicated space to comfortably provide FP services, increased financial support for camping and outreach, and integration of FP with other services. One respondent encouraged the government to continue utilizing the Camping Approach, so long as it is district-specific. 
"At district level we need more people to be trained in the family planning issues, more funding to improve the services for family planning, more infrastructure, more health centers and of course the maternity wings for mothers where mothers can go

and be free and interact with the staff at the clinic and talk about these family planning issues because people feel shy to interact if there are a lot of people."

-District-level respondent

"Let the family planning service be implemented and infused in the existing structure rather than it running parallel."

-District-level respondent

"The camping approach can still be integrated with other activities but that requires funding to continue such activities because you will need fuel, you will need transport, you will need the staff to do that."

-District-level respondent

"The CBDs were given just one bicycle, but this bicycle cannot be used by both the $C D B s$ because we have one is a women and the other one is a man. Another bicycle is better and this will help them and also motivate them."

-Facility-level respondent

"What we $[C B D$ s] were told when I went for training in Kabwe was that we will be getting K50 as missing lunch and health providers will be getting K100 but that has not happened."

-Community-level respondent

"There are certain aspects of the camping approach which they [the government] can do using what SUFP has done based on the kinds of funds we had. The government needs to understand that this has to be district specif-ic, it has to really depend on what the district can do, not what national level wants to do. They need to push it down to the communities to the families, let them decide on how best this approach can be done. We have trained people in the 26 districts; they can use the 26 districts as reference points so even if SUFP closes today, family planning is not closing."

-National-level respondent 


\section{Demand}

While the WHO Health Systems Framework does not address demand, given the focus on outreach and sensitizing communities, it is an important component of SUFP. Through outreach, SUFP educated local leaders about the importance of family planning, with the expectation that these influential community leaders would encourage community members to understand the significance of the services being offered.

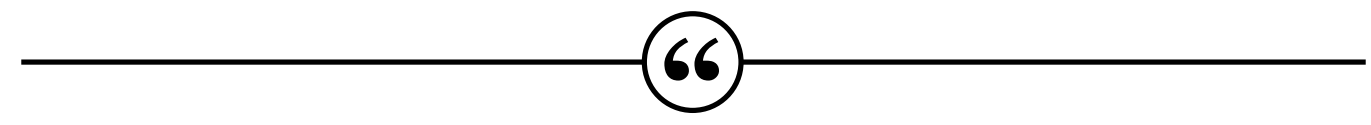

"SUFP has managed to help the head men and church leaders to see the importance

of family planning services in their communities and these leaders have in turn sensitized their communities on the importance of family planning. This has resulted

in a lot of community members accessing these services because these leaders are very influential and whatever they say is taken as gospel truth by the community members."

-District-level respondent

In the KII, the most commonly cited demand-side barriers to FP services included: actual or feared partner/ spousal disapproval, myths and misconceptions, and age (youth and adolescents).

Spousal disapproval and abuse were commonly mentioned as reasons for married women to avoid accessing FP methods.

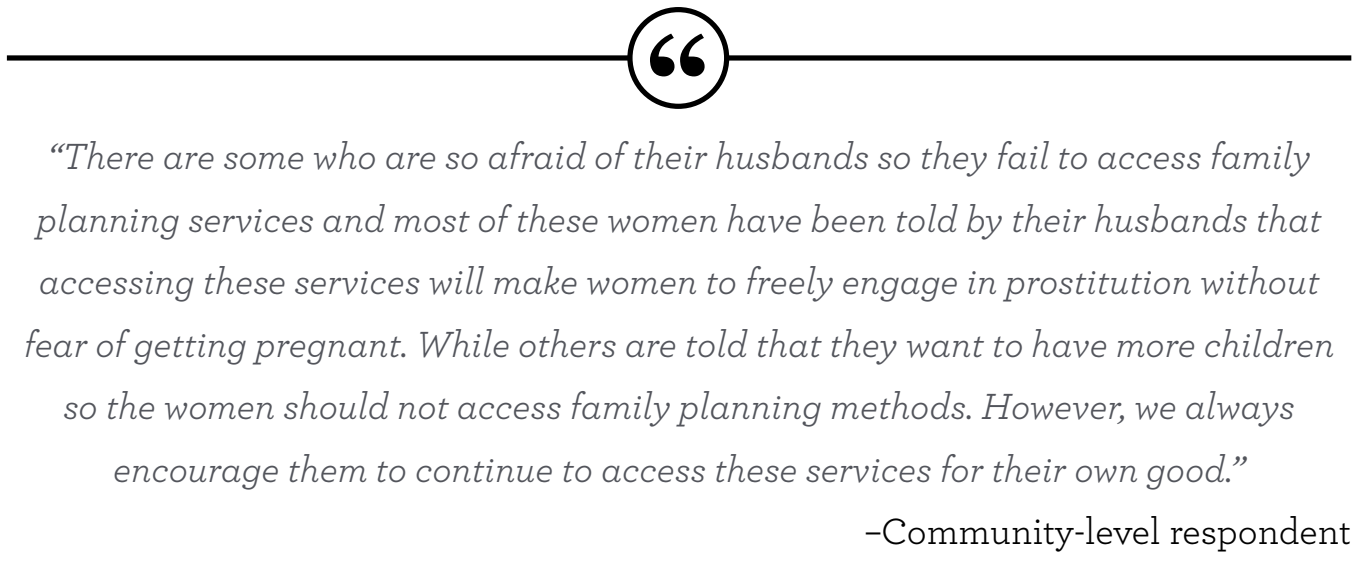

Myths and misconceptions also played a role in keeping women from accessing family planning.

"Last month when we went somewhere for an outreach activity, we found women who still believe that if you insert Jadelle it will go to your heart and you will die, while others believe that it leads to cancer."

-District-level respondent 
Adolescents are especially at risk of unwanted pregnancy, due to social norms that dissuaded providers from extending certain FP services and methods to young people. The project received push-back on reaching out to young people. Respondents recommended there should be continuous sensitization in the community to keep demand levels high, correct misunderstandings and educate the community.

\section{(6)}

"It was a big question with government and some parents, "why are you giving young ones contraceptives, what is your morality, are you encouraging immorality?' [We responded that] There are so many early marriages and once you cut the early marriage, children will still hide and do their things and they will get pregnant but if they are protected then they will not get pregnant and at least they will complete school without talking of pregnancy."

-District-level respondent

Respondents recommended there should be continuous sensitization in the community to keep demand levels high, correct misunderstandings and educate the community.

\section{6}

"They should continue with community mobilization, community sensitization, and community engagement. People are mobile, others are coming from towns telling them other things, others are coming from typical villages, misunderstanding the whole process and those who understand are misled. So sensitization must continue and community engagement must continue and whether we want it or not, whether the government wants it or not, they have to find resources from grants and continue FP services, it's a key to this intervention and it will yield results."

District-level respondent 


\section{POTENTIAL CHALLENGES WITH THE TRANSITION OF SUFP FROM PROJECT TO PROGRAM}

Respondents had mixed answers regarding how to move forward after the close of the SUFP project. Some respondents thought that the programming would continue.

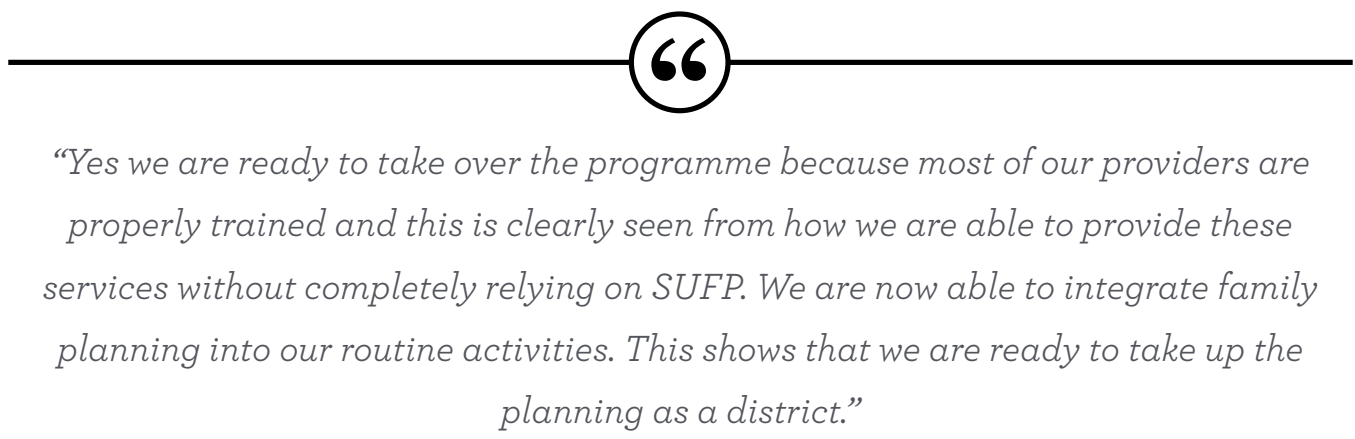

-District-level respondent

"We are sure that we will continue sustaining the programme as long as the health providers and the $C B D$ s that were trained continue working here then continue providing the services because we have the skills and knowledge."

-Facility-level respondent

Many more respondents identified major challenges with the transition of the SUFP strategy including: 1) shortage of commodities and equipment, (2) reduction of service provision and workforce, 3) potential reversal of effects on child bearing and / or maternal health, and 4) concerns that the government will be unable to sustain SUFP's level of support.

\section{6}

"SUFP has provided expensive equipment (kidney dishes, uteri forceps, and sterilizers) to most of our facilities, so if they close we know that these machines will break down and I think that the district will not afford to repair them or purchase them."

-District-level respondent "SUFP has been providing fuel and this has really helped us in mobilizing, sensitizing and conducting the camping approach."

-Facility-level respondent 


\section{6}

"I feel the government will not manage to supply these methods, this will result in an increase in the number of people who will be getting pregnant and they will be giving birth every year. Secondly, maternal deaths will also increase and all the problems that used to be there in the past will come back."

Community-level respondent "Just thinking for government, the problems that they are likely to face are that work that is shared is easier done, but when you have to do the work alone, it gets harder. It therefore will be difficult for government to manage facilitating these programs in all 26 districts in that some parts or aspects will suffer in the long run. When the government takes turns to move from district to district, the one district will always

$$
\text { suffer while waiting." }
$$

-Community-level respondent

Respondents were concerned that they would not be able to employ the Camping Approach and conduct outreach activities because it required fuel, transportation and daily subsistence allowances (DSAs). Without outreach activities, clients living in rural areas would be most affected because previously accessible FP services would no longer be within reach. Some respondents were concerned that their own jobs were about to end and were hoping a new donor-supported initiative would replace SUFP.

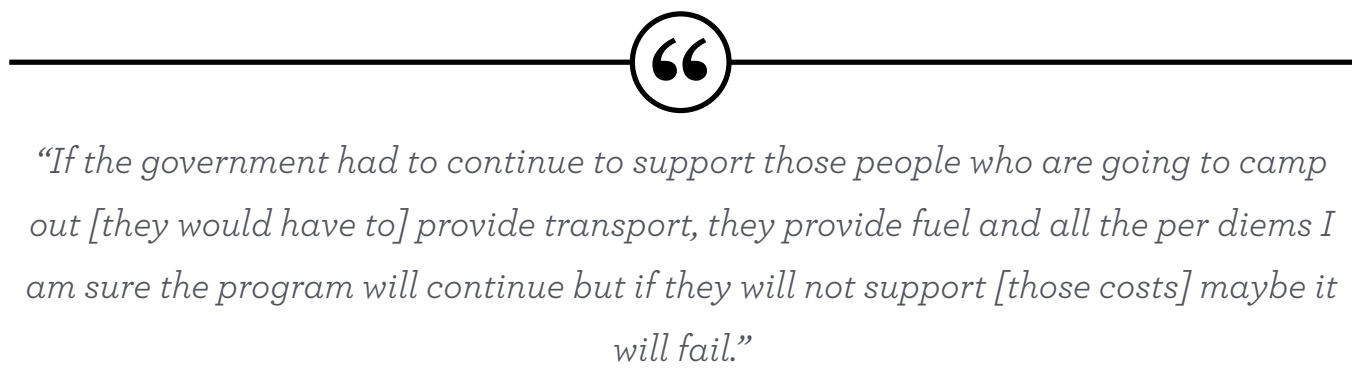

-Community-level respondent

"There will be a low turnout for FP because the women who live faraway will not be managing to come here for FP and the people at the facility won't be managing to follow them since SUFP will no longer be around. Some CBDs will stop because they were being motivated but if there is no motivation they will be feeling lazy to continue working in the community. With SUFP around there were no shortages of the FP methods so when they go it will be a challenge."

-Community-level respondent 


\section{Discussion and Recommendations}

The findings from the qualitative assessment show that respondents had a positive view of the contribution of SUFP and its engagement with the health system in Zambia. SUFP has been successful in scaling up increased access to FP commodities and services in the 26 districts reached under the project, and emphasizing the importance of FP within the selected communities. This report highlights the respondents' perceptions of the implementation of the overall SUFP program, including the Camping Approach, and their suggestions for moving the approach forward at the close of the project. While SUFP was widely viewed by respondents as successful in expanding access to FP and in strengthening services, they noted barriers to FP service delivery that generalize beyond SUFP and remain features of the health system that policymakers, researchers, and service providers need to be aware of when working to scale up family planning services.

Together with the costing component of the study (Part 2, Collins et al., 2016), these recommendations provide vital information for the government and donors to develop programming to continue the advances made under SUFP and to expand the approach to reach more districts in order to reach the country's FP2020 goal. Recommendations from respondents are organized under the six health systems building blocks, and demand.

\section{Leadership/Governance}

- Improve communication between NGOs and the government at district and sub-district levels to increase awareness of each organization's involvement in important activities. Better communication will also help improve accountability for NGOs and the government.

- Hire a full-time FP Coordinator to oversee the FP activities for each district. The presence of a coordinator who is committed completely to FP will allow adequate attention to FP issues that facilities and communities face on a daily basis.

- Encourage political buy-in for FP at the national level to ensure pressing FP issues (e.g. financing, quality of care, broad method mix at outpatient facilities) are not overlooked or neglected.

\section{Financing}

- Funds should be earmarked for FP activities, distinct from general MCDMCH grants. If FP is budgeted separately from maternal and child health, there may be better planning of outreach activities.

- Efforts to continue utilization and improve the efficiency and effectiveness of the SUFP strategy would benefit from partnering with other donor-supported initiatives. Funding can be sustained and outreach costs can be reduced by coordinating with other donor agencies, as well as integrating FP and the Camping Approach with other outreach and mobilization activities.

\section{Workforce}

- Train more CBDs and providers to ensure that there are enough staff members to address the increasing demand for FP services (at least one CBD per neighborhood). Increasing the number of trained personnel will improve the opportunities for clients to receive high quality care.

- Offer refresher training courses for employees, to support employees in their line of work. Refresher courses will help CBDs and providers feel confident in themselves and in the information they impart on their clients. 
- Compensate CBDs for their time and valuable work. Respondents have mentioned CBDs quitting due to lack of compensation, because compensation can financially incentivize CBDs to stay accountable and motivated.

- Supervise and evaluate staff members to ensure that accurate and suitable information is shared with clients. Supervision and evaluation will also keep employees accountable for their attitudes and delivering high quality care. Designated supervisors should be appointed, rather than relying on a rotation of nurses to fill these positions.

\section{Health Information Systems}

- Submit reports on time to help inform the district of the commodities that are low, before the facility is stocked out.

- Look for and adopt technologies to enhance the Health Information System to capture data more accurately and quickly.

\section{Access to FP Commodities}

- The government should identify strategies that improve method mix at lower level facilities, including the introduction of new FP methods, to improve client satisfaction levels. With a greater variety of methods, clients will be able to choose the method most comfortable to them.

- Educate CBDs on how to stock commodities to reduce the number of stock outs in the facility and community.

- Ensure that the government is delivering sufficient commodities to the facilities, to ensure that clients always have their preferred method available to them.

\section{Service Delivery}

- Increase availability of infrastructure to comfortably provide FP services to clients. Oftentimes clients are shy to access FP services; building new space or designating current space specifically for FP provision will help clients feel more comfortable accessing these services.

- Increase financial support for camping and outreach to reach clients in rural areas (at least K50, approximately US $\$ 5$, for CBDs and K100, approximately US $\$ 10$, for providers).

- Many clients depend on outreach activities but currently CBDs lack the necessary transportation to reach client. This issue may be improved by providing more than one bicycle per facility catchment area.

- Integrate FP activities with other services to reduce costs and increase opportunities for clients to access services.

- Make the Camping Approach specific to each district to ensure adequate use of funds. Some techniques may not be successful in every district, so it's important to know the strengths and weaknesses of each district.

\section{Demand}

- Continue sensitizing the community to correct misunderstandings, educate the community and keep demand levels high. Clients may forget what they are taught, so it's important to continue sensitizing the community and reinforcing the importance of FP. 


\section{References}

Central Statistical Office (CSO) [Zambia], Ministry of Health (MOH) [Zambia], and ICF International. (2014). Zambia Demographic and Health Survey 2013-14. Rockville, Maryland, USA: Central Statistical Office, Ministry of Health, and ICF International.

Collins. D, and Gilmartin. C. 2016. Scaling Up Family Planning in Zambia: Part 2. The Cost of Scaling-up an Innovative Program. Study Report. Washington, DC: Population Council, The Evidence Project.

Hainsworth G, Engel DM, Simon C, Rahimtoola M, Ghiron LJ. (2014). Scale-up of adolescent contraceptive services: lessons from a 5-country comparative analysis. J Acquir Immune Defic Syndr. 66 Suppl 2:S200-S208.

Huaynoca, S., Svanemyr, J., Chandra-Mouli V.C., Moreno Lopez, D.J. (2015). "Documenting good practices: scaling up the youth friendly health service model in Colombia." Reproductive Health. 18;12(1):90.

Keyonzo, N., et al. (2015). From Project to Program: Tupange's Experience with Scaling Up Family Planning Interventions in Urban Kenya. Reproductive Health Matters. 23(45). http://www.jhpiego.org/imgs/ kenya/pubs/Keyonzo_TupangeRHMatters.pdf. Accessed March 11, 2016.

Lundgren, R., Sinai, I., Jha, P., Mukabatsinda, M., Sacieta, L., \& León, F. R. (2012). Assessing the effect of introducing a new method into family planning programs in India, Peru, and Rwanda. Reprod Health, 9, 17. doi: 10.1186/1742-4755-9-17.

Ministry of Community Development, Mother and Child Health (MCDMCH), Republic of Zambia. (2013). Family Planning Services: Integrated Family Planning Scale-up Plan 2013-2020. Lusaka, Zambia: MCD$\mathrm{MCH}$.

Simmons, R. (2010). Nine steps for developing a scaling-up strategy. Geneva: World Health Organization.

World Health Organization (WHO). (2007). Everybody Business: Strengthening Health Systems to Improve Health Outcomes: WHO's Framework for Action. Geneva: World Health Organization.

WHO. (2010). Monitoring the Building Blocks of Health Systems: A Handbook of Indicators and their Measurement Strategies. Geneva: World Health Organization. ISBN: 9789241564052 


\section{Appendices}

\section{APPENDIX 1: KEY INFORMANT INTERVIEW GUIDE (DISTRICT, FACILI- TY, AND COMMUNITY LEVEL)}

Thank you for taking the time to speak with me today. I'm interested in learning about the current state of family planning service provision in your area and how family planning services have been implemented over the past few years. There are no 'good' or 'bad' answers to these questions; I would just like to know more about your opinions and experiences with family planning service implementation locally and nationally, particularly in the public sector.

- What does family planning (FP) mean to you?

- PROBE: Why is contraception important?

- Please describe the work you do related to FP.

- Who are the major actors in FP in your [district, facility catchment area, or community]?

Scaling Up Family Planning (SUFP) is a four-year programme funded by DFID that aims to increase contraceptive prevalence and reduce maternal mortality in Zambia through expanding access to FP services. In 26 districts across Zambia, SUFP set out to help the government to:

- Expand the choice of FP methods available, especially long-term reversible methods

- Increase access to FP services for underserved areas and populations

- Increase community support for family planning

- Increase capacity of government health facilities to provide high-quality, comprehensive family planning services

- Have you heard of the SUFP “Camping Approach"? Please how describe this approach was rolled out in your [district, facility catchment area, or community].

- Do you think there was a need to introduce this approach to your [district, facility catchment area, or community]? Why or why not?

- When did SUFP first begin implementing the "Camping Approach" in [district, facility catchment area, or community]? When did SUFP begin providing other types of support for family planning activities in your [district, facility or community]?

Now I would like to discuss the key factors that enable or may be a barrier to FP service provision in your [district, facility catchment area, or community]. I have several questions for us to discuss.

Leadership \& Governance

- How does leadership at every level from district, to facility, to community influence FP service provision and utilization?

- PROBE: District Medical Office and District Commissioner, facility in-charges, local leaders [e.g. Ward Councilors, chiefs, religious leaders, and school leaders]

- How are FP activities coordinated between the public sector, non-governmental organizations (NGOs, e.g. SUFP, SFH, Marie Stopes), and faith-based organizations (e.g. CHAZ or mission hospi- 
tal boards)? Who leads the coordination efforts? What could be done to improve the coordination?

- PROBE: How has SUFP influenced the support of leaders for FP in your [district, facility catchment area, or community]?

Financing

- Supply: Do you feel that enough funds are allocated to FP activities in your [district, facility catchment area, or community]? Please give specific examples to support your position.

- PROBE: How has SUFP influenced the amount of funds allocated for FP activities in [district, facility catchment area, or community]. Consider per diems, DS As \& transportation, or fuel money.

- Demand: Are there any formal user fees for FP services? Are there indirect costs that the user or client bears when seeking FP? And have you heard about informal fees for FP services?

- PROBE: are there informal fees to insert or remove the implant and IUD

- REMIND: the interviewee of indirect costs (transport, lost wages, etc.) and direct costs (commodities, register books any fees, etc.).

- How has SUFP influenced the costs for seeking FP services?

Service Delivery

- How would you describe the availability or accessibility of FP services in your [district, facility catchment area, or community]?

- Are there any cultural beliefs, practices, or expectations that limit FP service uptake in your [district, facility catchment area, or community]?

- PROBE: Are some women not accessing services based on: age, marital status, geographic location, means to pay, or male involvement?

- How would you describe the quality of FP services in your [district, facility catchment area, or community]? When we speak of "quality," we mean issues related to how women are treated when they go for FP services. For example, is the service provider's attitude respectful of the client's expressed preferences? When we speak of high quality FP, we mean more than "good" services, we mean respectful care that empowers the woman.

- PROBE: Is there enough space in the health facilities to provide a full range of short-and long-term methods? Is there enough privacy? Please explain.

- How has SUFP influenced the quality of FP services in in your [district, facility catchment area, or community]?

- PROBE: Are providers' attitudes changing?

Workforce

- Do you feel that the number of FP providers and CBDs in your [district, facility catchment area, or community] is adequate? Why or why not?

- How would you describe the knowledge and skill levels of the FP providers and CBDs in your [district, facility catchment area, or community]?

- PROBE: How has SUFP influenced on the availability of FP services in in your [district, facility catchment area, or community]?

- How does staff turnover and absenteeism influence FP service delivery? By absenteeism we mean staff that regularly fail to report to work on time. 
- PROBE: for turnover, attrition and absenteeism at district, facility and community levels as appropriate.

- How SUFP influenced staffing in your [district, facility catchment area, or community]?

Supplies

- Which methods of FP are available in your [district, facility catchment area, or community]? Probe for both short-term methods (condoms, pill, injectables) and long term methods (implant, IUD, sterilization).

- Have you experienced any local stock outs of any FP commodities? If yes, for which methods? What is the cause of these local stock outs?

- Have you experienced any challenges with the availability of equipment or supplies required for comprehensive FP services (e.g. sterilization equipment, disinfection supplies)?

- PROBE: How has SUFP influenced the FP supply chain in your [district, facility catchment area, or community]?

Information \& Research

- What type of data is routinely captured on FP service provision? Probe for registers for service delivery and stock status.

- How are service provision data counted at facilities and outreach? Are outreach activities recorded separately from facility service counts?

- What challenges do you face in your [district, facility catchment area, or community] in capturing and reporting these data?

- Do you use the family planning service delivery and stock status data collected in your [district, facility catchment area, or community]? If yes, how? What are the limitations of these data?

- PROBE: How has SUFP influenced the record-keeping for FP services and supplies in your [district, facility catchment area, or community]?

- Has implementation of SUFP's activities in your [district, facility catchment area, or community] changed at all over time? If yes, how so?

- What have been the challenges to implementing the "Camping Approach" in your [district, facility catchment area, or community]? What other challenges do you think SUFP has faced in supporting FP activities?

- PROBE: How were these challenges overcome?

- Have SUFP activities or support introduced any challenges to FP service provision in your [district, facility catchment area, or community]? If yes, please provide specific examples.

- PROBE: How were these challenges overcome?

- If you had to pick the greatest contribution of SUFP in your [district, facility catchment area, or community], what would it be and why?

- SUFP is a 4-year program currently scheduled to close in the beginning of 2016.

- In which ways, if any, has your [district, facility or community] prepared to take over the activities currently being supported by SUFP?

For District Medical Officer ONLY:

- What has been the primary function of the DOC? Has this been useful? How so or how not?

- Will a similar position be created for the district once the project closes? Why or why not? 
- If a position will not be created, will anyone take over the responsibilities of the DOC? If yes, which functions of the DOC will be continued? Who will assume these responsibilities?

- Which challenges do you expect the [district, facility or community] to face after SUFP closes?

- PROBE for challenges in management, coordination, and/or supervision, demand generation, supply of FP services

- In light of these challenges, how feasible do you think it will be for the government to implement the "camping" approach and sustain SUFP's level of support for FP activities in every district in Zambia as part of the public sector health system? Please explain.

- Which challenges do you expect the government to face in trying to implement these activities in every district? How can these challenges be overcome?

Recommendations for FP Scale UP

- The government has developed a plan to scale-up access to FP in Zambia.

- What does "scale-up" mean to you in this context?

- In what ways is FP being scaled-up in Zambia? Beyond SUFP, how is FP being scaled up in your [district, facility catchment area, or community]?

- What can be done to (further) improve efforts to scale-up FP services in Zambia? How can scale-up efforts be improved in your [district, facility catchment area, or community]?

- PROBE for recommendations to improve management, coordination, and/ or supervision, demand generation, supply of FP services 


\section{APPENDIX 2: STAKEHOLDER DISCUSSION GUIDE (NATIONAL LEVEL)}

Thank you for taking the time to speak with me today. I'm interested in learning about the implementation process in the Scaling up Family Planning project. There are no 'good' or 'bad' answers to these questions; I would just like to know more about your opinions and experiences with the SUFP project and sustainability of the approach after 2016.

Knowledge and attitudes towards family planning

- Please list all of the methods of FP available in [district]. For each method listed, ask:

- How effective is this method?

- Who is eligible to use this method? [Probe for age and marital status]

- What do community members in [district] think about FP? [Probe for community leaders, men, women]

- Who uses FP? [Probe for age and marital status]

- Which methods are most popular? Why?

- Are other health sector stakeholders in [district] supportive of FP? Please explain how or how not.

- PROBE for:

- District Medical Office (DMO) staff

- Doctors

- Nurses

- Pharmacists/chemists

- Volunteers [e.g. community-based distributors (CBDs), safe motherbood action groups (SMAGs), or other community bealth workers]

Factors that challenge and enable family planning service provision

- Please describe all of the factors that enable or serve as barriers to FP service provision in [district].

- Probe for comments on each of the following areas:

- Leadership \& Governance

- District Medical Officer

- Facility in-charges

- Local leaders [e.g. District Coordinators (DCs) and Ward Councilors]

- Coordination between public sector, non-governmental organizations (NGOs), and faith-based organizations (FBOs)

- Financing

- Supply: budget allocation for FP commodities

- Demand: FP service fees at facility, costs for FP commodities over the counter

- Service delivery

- Quality of care concerns?

- Are providers generally respectful of young people seeking FP? Is paternalism a problem?

- Is there any trust and confidentiality?

- Workforce 
- Number of trained providers?

- Staff turnover?

- Workload?

- Labor shortage in local areas of the district?

- Supplies

- FP method mix \& availability of each method

- Bottlenecks in supply chain?

- Information \& Research

- Are FP registers available and used by service providers in this district? Is service delivery monitoring effectively conducted?

- Is the bealth management information system (HMIS) operating as intended to track. FP service delivery?

Perceived impact of SUFP activities in district

- What is the current level of access to FP services in [district]?

- Please describe any positive or negative changes in access to FP services in [district] since 2012.

- [If any changes mentioned, ask:] What are the factors that contributed to this change in access to FP services in recent years? How has the SUFP project contributed to these changes?

- [If no changes mentioned, ask:] Why do you think that there have not been any changes in access to FP services in recent years?

- What is the current level of demand for FP services in [district]?

- Please describe any positive or negative changes in demand for FP services in [district] since 2012.

- [If any changes mentioned, ask:] What are the factors that contributed to this change in demand for FP services in recent years? How has SUFP contributed to these changes?

- [If no changes mentioned, ask:] Why do you think that there have not been any changes in demand for FP services in recent years?

- What is the current quality of FP services in [district]?

- Please describe any positive or negative changes in quality of FP services in [district] since 2012.

- [If any changes mentioned, ask:] What are the factors that contributed to this change in quality of FP services in recent years? How has SUFP contributed to these changes?

- [If no changes mentioned, ask:] Why do you think that there have not been any changes in demand for FP in recent years?

Recommendations for FP scale-up

- What can be done to (further) improve efforts to scale-up family planning services in [district]?

- What can be done to increase access?

- What can be done to increase demand?

- What can be done to improve quality? 

INTERVIEWS

\section{Workforce}

- Health system barriers/challenges to FP service delivery

- SUFP engagement with health system

- Work force quality of care

- Recommendations

\section{Leadership/Governance}

- Major actors and their roles

- District level

- Facility level

- Community level

- Public Sector and NGOs

- Health system barriers/challenges to FP service delivery

- SUFP engagement with health system

- Recommendations

\section{Health Information Systems}

- Types of data collected \& data use

- Health system barriers/challenges to FP service delivery

- SUFP engagement with health system

- Recommendations

\section{Access to Family Planning Commodities}

- FP method mix

- Health system barriers/challenges to FP service delivery

- SUFP engagement with health system

- Recommendations

\section{Financing}

- Health system barriers/challenges to FP service delivery

- SUFP engagement with health system

- Recommendations

\section{Service Delivery}

- Description of Camping 
- Health system barriers/challenges to FP service delivery

- SUFP engagement with health system

- Recommendations

\section{Demand}

- Health system barriers/challenges to FP service delivery

- Age

- Male involvement/marital status

- Geography

- Myths and misconceptions

- Other

- SUFP engagement with health system

- Recommendations

\section{Phase-out of SUFP}

- Existing plans to continue without SUFP

- Challenges/impact of SUFP closing

- Recommendations for government sustaining SUFP activities

\section{Family Planning \& Scale Up}

- Importance of family planning and contraception

- Scale-up definition

- Current FP scale-up activities in Zambia and community

- FP scale-up beyond SUFP

- Recommendations for FP scale-up 
The Evidence Project

Population Council

4301 Connecticut Avenue, NW, Suite 280

Washington, DC 20008 USA

tel +12022379400

evidenceproject.popcouncil.org 